FEDERAL RESERVE BANK OF SAN FRANCISCO

WORKING PAPER SERIES

\title{
Pricing Poseidon: Extreme Weather Uncertainty and Firm Return Dynamics
}

\author{
Mathias S. Kruttli \\ The Board of Governors of the Federal Reserve System \\ Brigitte Roth Tran \\ Federal Reserve Bank of San Francisco \\ Sumudu W. Watugala \\ Cornell University \\ January 2023
}

Working Paper 2021-23

https://www.frbsf.org/economic-research/publications/working-papers/2021/23/

\section{Suggested citation:}

Kruttli, Mathias S., Brigitte Roth Tran, Sumudu W. Watugala. 2023 "Pricing Poseidon: Extreme Weather Uncertainty and Firm Return Dynamics," Federal Reserve Bank of San Francisco Working Paper 2021-23. https://doi.org/10.24148/wp2021-23

The views in this paper are solely the responsibility of the authors and should not be interpreted as reflecting the views of the Federal Reserve Bank of San Francisco or the Board of Governors of the Federal Reserve System. 


\title{
Pricing Poseidon: Extreme Weather Uncertainty and Firm Return Dynamics*
}

\author{
Mathias S. Kruttli, Brigitte Roth Tran, and Sumudu W. Watugala ${ }^{\dagger}$
}

January 2023

\begin{abstract}
We present a framework to identify market responses to uncertainty faced by firms stemming from extreme weather events. Stock options of firms with establishments in a hurricane's landfall region exhibit large, long-lasting implied volatility increases, reflecting significant uncertainty. Analyst calls show correspondingly persistent discussions of hurricane impacts on hit firms, which reveal business interruption and physical damages as dominant real channels. Comparing ex ante implied volatility to ex post realized volatility by analyzing volatility risk premia differences shows investors significantly underestimate extreme weather uncertainty until Hurricane Sandy. Despite constituting local, idiosyncratic volatility shocks, extreme weather events affect expected returns.
\end{abstract}

JEL classification: G12, G14, Q54.

Keywords: extreme weather, uncertainty, implied volatility, expected returns, climate risks.

*We are grateful to our discussants Lint Barrage, Michael Bauer, Riccardo Colacito, Ben Groom, Matthew Gustafson, Burton Hollifield, Kris Jacobs, Scott Mixon, Zacharias Sautner, Aurelio Vasquez, and Andrea Vedolin. We thank Jawad Addoum, Rui Albuquerque, Vicki Bogan, Mikhail Chernov, Byoung-Hyoun Hwang, Andrew Karolyi, Fang Liu, Ian Martin, Dimitri Muravyev, Justin Murfin, David Ng, Emilio Osambela, Andrew Patton, Tarun Ramadorai, Brian Seok, Greg Vilkov, Scott Yonker, Youngsuk Yook, and seminar participants at the Federal Reserve Board, Cornell University, Indiana University, Johns Hopkins University, University of Zurich, NOAA, UCSD, UCSB, Harvard Kennedy School Northeast Workshop, CEPR-EBRDEoT-LSE Workshop, Resources for the Future, ECB Symposium on Climate Change, Finance, and Green Growth, UCLA Luskin Symposium on Climate Adaptation, University of Oklahoma Energy and Commodities Finance Research Conference, Stanford SITE Conference, NBER Asset Pricing Spring Meeting, and AFA for helpful comments. Keely Adjorlolo, Gus Kmetz, David Rubio, and Alan Yan provided outstanding research assistance. The views stated herein are those of the authors and are not necessarily the views of the Federal Reserve Board, the Federal Reserve Bank of San Francisco, or the Federal Reserve System.

${ }^{\dagger}$ Kruttli: Federal Reserve Board. Email: mathias.s.kruttli@frb.gov. Roth Tran: Federal Reserve Bank of San Francisco. Email: brigitte.rothtran@sf.frb.org. Watugala: Indiana University. Email: sumudu@iu.edu. 


\section{Introduction}

From hurricanes and severe snow storms to floods and droughts, extreme weather events have caused widespread devastation in recent years. For instance, in the record year of 2017, the estimated damages from extreme weather events in the U.S. were over $\$ 300$ billion. $^{1}$ While the unpredictable impacts of extreme weather on a firm's continuity of operations and business environment could create significant uncertainty, firms can potentially offset these effects through insurance or adaptation. Thus, it is not obvious a priori that extreme weather events generate substantial uncertainty for firms. Despite an emerging climate finance literature and policymaker concerns that mispricing of climatic events in asset markets could lead to sudden price corrections and threaten financial stability, little is known about the uncertainty that is generated by extreme weather events for firms or how such uncertainty is priced. ${ }^{2}$

In this paper, we first use financial markets to isolate and quantify the extent of extreme weather uncertainty faced by firms, and then analyze the pricing of this uncertainty. ${ }^{3}$ The exogenous, identifiable nature of extreme weather events allows us to isolate the associated uncertainty cleanly, because prevailing conditions of the firm do not affect the timing and likelihood of such events. Extreme weather events are also local, and thus, impact only a subset of firms in the economy, creating a unique experimental setting. 4 This allows us to thoroughly investigate first order questions in asset pricing, including on informational efficiency and whether idiosyncratic shocks impact asset prices not only through the cash flow channel but also through the discount rate channel, as in Merton (1987).

We ground our empirical analyses on a simple theoretical framework that distinguishes between the "incidence uncertainty" faced by a firm regarding whether it will be hit by an

\footnotetext{
${ }^{1}$ National Oceanic and Atmospheric Administration (NOAA) damage estimates (https://www.climate. gov/news-features/blogs/beyond-data/2017-us-billion-dollar-weather-and-climate-disasters-historic-year).

${ }^{2}$ Government agencies responsible for the resilience of the financial system have begun examining the potential impact of climatic events. The Federal Reserve's Financial Stability Report, November 2020: "...uncertainty about the timing and intensity of severe weather events and disasters, as well as the poorly understood relationships between these events and economic outcomes, could lead to abrupt repricing of assets." (https://www.federalreserve.gov/publications/ 2020-november-financial-stability-report-near-term-risks.htm).

${ }^{3}$ As in this paper, Bloom (2009); Pastor and Veronesi (2012, 2013); Jurado, Ludvigson, and Ng (2015) and others define uncertainty as expected volatility, distinct from the literature on Knightian uncertainty.

${ }^{4}$ Because extreme weather events are local and idiosyncratic, they differ from the market-wide shocks considered in the disaster risk literature as in Barro (2006).
} 
extreme weather event, and the "impact uncertainty" about the event's effect on the firm conditional on it being hit. Although our theoretical framework applies to extreme weather events broadly, we focus our empirical analyses on hurricanes due to three key features that enable identification. First, hurricanes are among the most economically destructive extreme weather events. ${ }^{5}$ States all along the Atlantic and Gulf coasts of the US, which include a wide variety of major centers of economic activity, have been impacted by hurricanes. Second, NOAA publishes a range of relevant data on hurricane forecasts and realizations. These data are accessible to investors in real time. Third, hurricanes develop from inception at sea and resolve following landfall or dissipation over fairly short but well-defined time frames.

We estimate the firm-level uncertainty generated by extreme weather events using changes to the implied volatility of stock options, a measure that captures investor expectations of volatility (see, for example, Bloom (2009)). We collect novel data from NOAA on hurricanes spanning 24 years. We combine those data with location data on the establishments of individual firms to construct a granular dataset that allows us to measure firm exposure to regions affected by each hurricane, which determines treatment in our difference-in-differences analysis.

Indicative of substantial impact uncertainty, we find that the implied volatilities of firms with exposed establishments are significantly elevated following hurricane landfall, rising up to 18 percent higher than before the hurricane's inception. ${ }^{6}$ Implied volatilities remain elevated for several months after hurricane landfall, suggesting that the resolution of impact uncertainty is slow. Mirroring this persistence in volatility, in a systematic textual analysis of the transcripts of calls between analysts and firm management, we find that discussions of hurricanes jump after landfall for hit firms relative to control firms, and remain elevated for a similar length of time. Ongoing discussions in analyst calls about a hurricane likely occur when its impact on a firm's performance is material but as yet unclear.

Volatility persistence is the basis for the large literature on autoregressive conditional heteroskedasticity models starting with the seminal work by Engle (1982). However, less is

\footnotetext{
${ }^{5}$ For instance, in $2017, \$ 265$ billion of the aforementioned $\$ 300$ billion in damages from extreme weather events in the US were due to hurricanes.

${ }^{6}$ We note here that unlike at the aggregate market level, stock returns and volatility at the firm level generally exhibit positive contemporaneous correlation as shown in Duffee (1995); Albuquerque (2012); Grullon, Lyandres, and Zhdanov (2012). As such, since our analysis is on firm-level volatility, the negative returnvolatility relationship documented for market index volatility is not impacting our results.
} 
known about the economic mechanisms underlying why volatility can be persistent, because it is difficult to identify exogenous shocks to the volatility of a treated group but not a control group - a challenge this paper can overcome. Our results indicate that learning about how a firm is impacted by a specific event takes time, and this constitutes an important driver of volatility persistence.

The accuracy of investor expectations of the uncertainty generated by extreme weather events is important given the role of volatility in determining, for instance, the risk associated with investment decisions, the cost of hedging physical climate risks, and option prices. We analyze how volatility risk premia (VRP) — computed as the difference between option-implied volatility and the subsequent realized volatility of the underlying stock over the remaining life of an option - change due to a hurricane. We find that the VRP of firms exposed to a hurricane are substantially lower for over a month, compared to the concurrent VRP of control firms with no exposure to the hurricane. This result implies that investors underreact to the volatility caused by a hurricane and do not efficiently update their volatility expectations based on the information available about firm establishment locations and where a hurricane made landfall. Interestingly, after Hurricane Sandy in 2012 - an unprecedented, highly damaging event that hit the financial center of the US - this underreaction to hurricanes diminishes, suggesting that the informational efficiency of markets improved after a particularly salient event that was personally experienced by many investors. These findings contribute to our understanding of volatility expectation formation after specific, exogenous shocks. Other research in the volatility literature finds that investors fail to correctly update expectations based on the realized volatility over the preceding months (Cheng, 2019; Lochstoer and Muir, 2022). The underreaction we document is a distinct phenomenon from the extrapolation of preceding realized volatility - the inception of a hurricane is an exogenous event that is unrelated to preceding realized volatility. ${ }^{7}$

We analyze the real economic channels behind the documented uncertainty and underreaction by exploiting the paper's focus on well-identified shocks. Through a systematic textual analysis of the transcripts of calls between analysts and managers of hit firms in the aftermath of a hurricane, we identify five channels that are mentioned frequently during communications about hurricane impacts: business interruption, physical damages, insurance,

\footnotetext{
${ }^{7}$ Other major events that are largely unexpected, for example, a pandemic or other geopolitical crisis, lead to spikes in expected volatility and are also not necessarily preceded by high realized volatility.
} 
demand, and supply. Discussions between managers and analysts (and investors) about a hurricane generally fall into these categories following a landfall. These mentions increase with a firm's exposure to the hurricane landfall region, with business interruption and physical damages channels being discussed most frequently, followed by demand and insurance channels. The supply channel generates the strongest investor underreaction as measured by VRP, consistent with the prior literature showing investors are inattentive to shocks to suppliers (see, for example, Menzly and Ozbas (2010)). Investors also underreact, to a lesser extent, to the business interruption, physical damages, and demand channels. Interestingly, investors do not underreact to the uncertainty generated through the insurance channel, suggesting that investors pay more attention and/or have a better understanding of the extent of delays and disputes that can occur for firms dealing with insurance firms.

We next analyze whether investors demand compensation for the extreme weather uncertainty faced by firms. Levy (1978) and Merton (1987) show theoretically how such idiosyncratic volatility can be "priced", and thus, impact discount rates because, in practice, investors may be underdiversified and unable to hold the market portfolio as predicted by the capital asset pricing model. In a simple extension to our theoretical framework, we explicitly show how extreme weather uncertainty can impact both cash flows and expected returns of a firm. We analyze this question empirically in two ways. First, we decompose the stock return variance of firms into cash flow news and discount rate news by using earnings per share forecasts and the methodology in Chen, Da, and Zhao (2013). The discount rate news and cash flow news shares of the return variance of hurricane-hit and control firms indicate that hurricanes drive stock price variation through both cash flow and discount rate channels. Second, we go one step further and test for evidence of higher expected returns due to the increase in expected idiosyncratic volatility in the aftermath of a hurricane hit. Prior papers such as Ang, Hodrick, Xing, and Zhang (2006) and Fu (2009) have empirically tested the Merton (1987) prediction assuming a particular volatility model or factor structure for stock returns and arrived at mixed conclusions. ${ }^{8}$ We contribute to this debate by exploiting our empirical setting, which allows us to isolate exogenous increases to idiosyncratic uncertainty

\footnotetext{
${ }^{8}$ Martin and Wagner (2019) derive excess return predictions from option prices. Their analysis focuses on the pricing of firm-specific sensitivity to aggregate volatility shocks like the global financial crisis, not shocks to purely idiosyncratic volatility. Here, we isolate and examine variation in firm-specific idiosyncratic volatility, independent of market-wide shocks.
} 
faced by firms. ${ }^{9}$ While in the early sample we do not find an impact on expected returns, after Hurricane Sandy, when volatility expectations are more accurate, there is strong evidence that firms with higher idiosyncratic volatility due to hurricane exposure have significantly higher expected stock returns.

The results discussed thus far focus on the uncertainty post landfall, which our theoretical framework shows captures impact uncertainty. Next, we analyze the uncertainty before landfall, which captures both incidence uncertainty and expected impact uncertainty, by using real-time forecasts of hurricanes predicted to make landfall as well as seasonal outlooks. We show that exposure to the forecast path of a hurricane increases firm implied volatilities even at low forecasted probabilities. In line with our theoretical framework, we find that implied volatility responses tend to increase up to a point with the probability of an extreme weather event occurring, increasing as much as 22 percent for hurricane wind speed probabilities of at least 50 percent. In contrast, we do not find evidence of significant responses to seasonal outlooks, which are much less informative than the forecasts for individual hurricanes. Whether or not investors pay attention and price in climatic events before they occur is an important question in the climate finance literature. For example, Carney (2015) discusses how the sudden repricing of climate events can be a threat to financial stability. Our analysis suggests that informative forecasts of extreme weather events are more quickly incorporated into asset prices.

Finally, we conduct a series of robustness checks and additional extensions. We show that our findings hold across and within industries, are not driven by small firms, are robust to the exclusion of individual hurricanes, to measuring firm exposure based on the location of its sales instead of establishments, and to alternative definitions of landfall regions. While financial firms are excluded from our baseline analyses, we show that the single-stock options of property and casualty insurance firms also reflect substantial extreme weather uncertainty. Further, exposure to hurricanes increases the dispersion of hit firms' abnormal cumulative returns and leads to both underperforming and outperforming hit firms compared to control firms at the tails of the distribution, indicating that these events do not only pose downside risk. In line with our general framework, we find that firm-level uncertainty also increases

\footnotetext{
${ }^{9}$ Each hurricane can be considered an exogenous idiosyncratic shock in this context because it affects a subset of firms distributed across different industries. The vast majority of firms within the market will be unaffected by a specific hurricane. Also, the sets of affected firms will vary for each hurricane.
} 
in response to exposure to extreme weather events other than hurricanes.

Given the focus on idiosyncratic shocks to volatility expectations, the efficient pricing of these expectations, and the implications for cash flows and discount rates, this paper is distinct from recent work in climate finance. Other papers in this literature investigate if stock prices efficiently react to extreme weather events and find evidence of both underreaction (see Hong, Li, and $\mathrm{Xu}$ (2019) on how drought indices predict food company stock returns) and overreaction (see Alok, Kumar, and Wermers (2020) on mutual fund performance following natural disasters). Further work focuses on the pricing of a transition to a low carbon economy, as opposed to physical climatic events, with Ilhan, Sautner, and Vilkov (2021) analyzing option markets and finding that the protection against downside risk is costlier for carbon-intense firms due to climate policy uncertainty. Others, for example, Andersson, Bolton, and Samama (2016); Roth Tran (2019); Engle, Giglio, Kelly, Lee, and Stroebel (2020); Bolton and Kacperczyk (2021); Baker, Hollifield, and Osambela (2022); Sautner, van Lent, Vilkov, and Zhang (2022a,b) study stock markets and transition risks. The fact that this transition has not materialized as yet makes it difficult to assess whether financial markets efficiently price such risks.

This paper not only contributes to our understanding of a new type of uncertainty within the broader uncertainty literature, but the unique features of extreme weather shocks yield an experimental setting that allows for a rich exploration of key questions in asset pricing. Because the events we study are identifiable, exogenous, and idiosyncratic, our analysis differs from other types of uncertainty studied in the literature like macroeconomic or political uncertainty, where periods of uncertainty are generally endogenous to prevailing conditions of the economy or firm. ${ }^{10}$

The remainder of this paper is structured as follows. We describe our data and research design in Sections 2 and 3, respectively. Section 4 presents our main results, followed by extensions and robustness tests in Section 5. We conclude in Section 6.

\footnotetext{
${ }^{10}$ See, for example, Bloom (2009); Jurado, Ludvigson, and Ng (2015); Baker, Bloom, and Davis (2016); Dew-Becker, Giglio, Le, and Rodriguez (2017); Hassan, Hollander, Van Lent, and Tahoun (2019). Some studies on political uncertainty like Julio and Yook (2012); Kelly, Pastor, and Veronesi (2016); Jens (2017) focus on prescheduled political events, which are interpreted as known, exogenous points in time when a policy (or regime) change might occur. However, the likelihood of whether a policy/regime change occurs on the prescheduled date can still be endogenous to prevailing economic conditions. As Pastor and Veronesi (2012) discuss, such a change is more likely during downturns.
} 


\section{Data and summary statistics}

Our analyses use data from a range of sources. We combine NOAA data on hurricanes with firm establishment data from the National Establishment Time-Series (NETS) database. We obtain stock data from CRSP-Compustat, options data from OptionMetrics, and earnings forecast data from IBES. Our source for analyst call transcripts is Refinitiv. We describe each of these data sources below.

\subsection{Hurricane data}

Hurricanes are tropical cyclones with high-speed surface wind that rotates counter-clockwise around an "eye." While the air is calm inside the eye, the eyewall has intense winds which radiate outward in a spiral fashion. These winds can reach a diameter of up to several hundred miles. Hurricanes originate in the ocean as tropical depressions, strengthening into tropical storms and then hurricanes as they traverse across water and sometimes over land before dissipating. The point at which a hurricane eye crosses from the ocean to land is called landfall. At landfall, hurricanes deliver not only intense winds that can exceed 100 miles per hour, but also significant rainfall and storm surge, both of which can cause major damage through flooding. After landfall, hurricanes continue to move over land, bringing strong winds and rain with them. In the US, hurricanes typically occur between June and November and are most common along the Gulf Coast and the southern portion of the Atlantic coast.

We use NOAA hurricane track data to identify hurricane landfall regions for 37 hurricanes from 1996-2019. These data show the actual location and intensity of each hurricane's eye at six hour intervals. To account for the fact that hurricanes impact counties not located in immediate proximity to the eye of the storm, we consider a county to be in the hurricane landfall region if the county's centroid lies within a specified radius of the hurricane eye within a 24-hour window before and after landfall. ${ }^{11,12}$ This window ensures that we capture

\footnotetext{
${ }^{11}$ We also consider other time windows, for example, within 12, 36, and 48 hours before and after landfall, and the results are qualitatively similar.

${ }^{12}$ Two hurricanes in the sample, Charley in 2004 and Katrina in 2005, made two landfalls in the US. To avoid double-counting these hurricanes, the date when the hurricane made landfall at a higher wind speedcorresponding to a higher storm category on the Saffir-Simpson scale - is considered the landfall date in our analysis. Including both landfalls for each hurricane in the analysis leads to qualitatively similar results.
} 
counties that lie more inland and, for hurricanes that move along the coast before turning inland, counties that were close to the eye of the hurricane before landfall. Figure 1 shows which counties fall within 50, 100, 150, and 200 miles of the eye of hurricanes Katrina (2005), Sandy (2012), Matthew (2016), and Harvey (2017). Table 1 panel A lists the hurricanes in our landfall sample. We present additional details on landfall data in the Internet Appendix.

Importantly, the landfall data we use are published by NOAA in real time, meaning that investors can know the landfall region of a hurricane as soon as it makes landfall. Other papers that do not focus on market pricing use damaged counties to discern the firms affected by natural disasters (for example, Barrot and Sauvagnat (2016b) and Dessaint and Matray (2017)). In our setting, using damage data would introduce a forward-looking bias because financial market investors do not know at the time of hurricane landfall which counties will experience damage from a hurricane - this is part of the uncertainty. County-specific damage estimates only become available with a substantial lag of up to several months.

In addition to the landfall data employed in our baseline analyses, we draw on two types of NOAA forecast data for the pre-landfall analyses. First, we use National Hurricane Center (NHC) wind speed probability forecast advisories to measure firm exposures to specific storms prior to landfall or dissipation. These text-based advisories - which capture the same underlying model outputs as commonly viewed forecast maps published by media outlets - are released publicly in real time as storms evolve to communicate probabilities of hurricane-speed winds occurring in particular locations. Second, to examine seasonal dynamics, we use NOAA's annual May outlook announcements of the probability of the upcoming hurricane season being above-normal in terms of the number of hurricanes. We discuss how we use these data in Section 4.5 and provide further details in the Internet Appendix.

\subsection{Firm establishment data}

We use NETS firm establishment location data to precisely estimate a firm's exposure to each hurricane. These data, which have been used in several other studies, ${ }^{13}$ contain establishment location information and are updated annually each January. Figure 2 shows the number

\footnotetext{
${ }^{13}$ For example, Neumark, Wall, and Zhang (2011) investigate the job creation of small businesses based on NETS. Addoum, Ng, and Ortiz-Bobea (2020) use NETS to analyze the effect of temperature fluctuations on firm sales. Although we use NETS establishment rather than sales data (because the latter are often imputed), an analysis using county-firm level sales instead of county-firm establishment counts yields qualitatively similar results.
} 
of establishments per county sorted into deciles using NETS data for 2010, illustrating that economic activity as measured by the density of firm establishments is high in areas exposed to hurricanes along the Atlantic and Gulf Coasts.

\subsection{Financial data}

We obtain daily data on single-name stock options from OptionMetrics. We use data from traded options with non-missing pricing information in OptionMetrics that are slightly outof-the-money. As discussed in previous studies on stock options, such options are more liquid and have a relatively small difference due to any potential early-exercise premium between American versus European options (see, among others, Carr and Wu (2009); Kelly, Pastor, and Veronesi (2016); Martin and Wagner (2019)). We apply standard filters to the options data consistent with the existing literature. In our sample, we include single-stock options which meet the following criteria: (i) standard settlement, (ii) a positive open interest, (iii) a positive bid price and bid-ask spread (valid prices), (iv) the implied volatility estimate is not missing, (v) greater than 7 days and at most 200 calendar days to expiry, and (vi) an option delta, $\delta$, that satisfies $0.2 \leq|\delta| \leq 0.5$. The estimate for the average implied volatility of firm $i$ at time $t$ is

$$
I V_{i, t}=I V_{i, t, M}=\frac{1}{Z} \sum_{z=1}^{Z} I V_{i, z, t, M},
$$

where $M$ is the nearest-to-maturity expiration at time $t$ of options on firm $i$ stock, which satisfy the above six criteria and $Z$ is the number of valid options for firm $i$ with that expiry. Here, $I V_{i, t, M}$ proxies for the ex ante risk-neutral expected value of the future stock return volatility of firm $i$ between time $t$ and $M .{ }^{14}$ While we use a model-based measure of implied volatility for our analysis, we show in Internet Appendix Section C.6 that our results are robust to using model-free implied volatility.

The stock return data are from CRSP-Compustat. We use standard stock return filters. To ensure that stocks with stale prices are excluded from our analysis, we require share prices of at least $\$ 5$ (Amihud, 2002) and exclude micro-cap stocks, defined as stocks in the bottom 20 percent in terms of market capitalization of listed equity (Fama and French, 2008).

Data on the consensus forecast of firm earnings per share used for our analysis on discount

\footnotetext{
${ }^{14}$ This measure of $I V_{i, t}$ is similar to that used in Kelly, Pastor, and Veronesi (2016) for options on international stock indices.
} 
rate and cash flow news are from the Institutional Brokers' Estimate System (IBES). To examine the real channels through which firms are affected by hurricanes, we obtain Refinitiv analyst call transcripts. We describe how we use the analyst call data in Section 4.3.

We link the firms in NETS to those in CRSP-Compustat through firm name and headquarter address. The matched sample is then linked to OptionMetrics, IBES, and Refinitiv using common firm identifiers. More details on this mapping are in the Internet Appendix. Our linked sample starts in 1996, the first year of the OptionMetrics data, and ends in 2019. Because financial firms' geographic exposure to extreme weather events may not be reflected by their establishment locations and financial firms are generally excluded in asset pricing studies, our baseline analyses exclude all financial firms by dropping firms with SIC numbers from 6000 to 6799. We separately analyze insurance firms, as described in Section 5.5.

We report summary statistics on our sample of firms in Table 2. Panel A shows that we have 3,196 unique firms in our sample. For comparison, we also show summary statistics for the set of firms that have significant exposure to a hurricane at least once in our sample period. A firm is included in this subsample of "hit" firms if it had at least $25 \%$ of its establishments within a 200-mile radius around the eye of at least one hurricane. This subsample includes 1,590 firms. On average, a firm has 126 establishments in a given year. For the subsample of hit firms, the average number of establishments is 129 . The hit firms are also comparable to the non-hit firms in terms of market capitalization, with a $\$ 5.9$ billion average market capitalization for hit firms and an average of $\$ 5.7$ billion for all firms. The slightly higher market capitalization for hit firms might be due to the higher economic activity in coastal regions. The summary statistics of the option measures are also similar between the total sample and the subsample of hit firms. The average (annualized) IV and VRP for all firms are 48.0 and 5.0 percent, respectively.

Table 2 Panel B reports summary statistics on firm exposure to hurricane landfalls. For landfall regions based on the 200- and 50-mile radii around the eye of the hurricane, the average U.S. firm has $7 \%$ and 1\%, respectively, of its establishments in a given landfall region. These values are reasonable as each hurricane generally only affects a few states and our sample encompasses firms across the US. Columns 5 to 8 show that our sample includes a large number of firms with a high share of their establishments within a landfall region. For example, for the 200- and 50-mile radii, we have 2,734 and 190 firm-hurricane observations, respectively, that at least once had $25 \%$ or more of their establishments in a landfall region. 


\section{Research design}

\subsection{Extreme weather uncertainty}

In this section, we discuss a simple framework for extreme weather uncertainty. More details and extensions of the framework are in Internet Appendix A where, adapting Merton (1987), we relate extreme weather events to return volatility, cash flows, and expected returns.

When a firm is located in an area in which an extreme weather event occurs, the operations of the firm can be impacted through a range of channels. For example, the extreme weather event can cause damage to the physical property of the firm, or demand for the firm's products can increase as part of the rebuilding process. However, the ultimate impact on the firm might not be immediately discernible at the time of the event, and this is what we coin the impact uncertainty of an extreme weather event.

More formally, we specify firm $i$ 's one period return at $t+1$, when the firm will be hit by an extreme weather event as

$$
\tilde{R}_{i, t+1}=\bar{R}_{i}+b_{i} \tilde{Y}_{t+1}+\sigma_{i} \tilde{\epsilon}_{i, t+1}+\tilde{g}_{i, t+1}
$$

where $\tilde{g}_{i, t+1}$ is a random variable that captures the impact of the extreme weather event on firm $i$ that is distributed with mean $\mu_{g, i}$ and variance $\sigma_{g, i}^{2} . \sigma_{g, i}^{2}$ captures the impact uncertainty. This definition of uncertainty as the variance of an unpredictable disturbance is in line with, for example, Pastor and Veronesi (2012, 2013); Jurado, Ludvigson, and Ng (2015). The other return components are independent of the extreme weather event. $\bar{R}_{i}$ is a

drift term, $\tilde{Y}_{t+1}$ is the market factor to which firm $i$ has a sensitivity of $b_{i}$, and $\sigma_{i} \tilde{\epsilon}_{i, t+1}$ is the product of a scalar $\sigma_{i}$ and random variable $\tilde{\epsilon}_{i, t+1}$ that has a mean of zero and variance of 1 .

Impact uncertainty is one component of extreme weather uncertainty and is conditional on the firm being hit by an extreme weather event. However, because the occurrence of an extreme weather event is unpredictable, there is uncertainty about whether an extreme weather event will hit a firm. Therefore, our framework specifies a second component of extreme weather uncertainty that we call incidence uncertainty - the uncertainty about whether an extreme weather event will occur where the firm is located. We can expand the return specification in equation (2) to account for the uncertainty of a firm being hit by an extreme weather event as follows 


$$
\tilde{R}_{i, t+1}=\bar{R}_{i}+b_{i} \tilde{Y}_{t+1}+\sigma_{i} \tilde{\epsilon}_{i, t+1}+\tilde{g}_{i, t+1} \tilde{\theta}_{i, t+1}
$$

where the random variable $\tilde{\theta}_{i, t+1}$ indicates whether firm $i$ is hit by the extreme weather event. $\tilde{\theta}_{i, t+1}$ has a Bernoulli distribution (one draw of a binomial distribution), $\tilde{\theta}_{i, t+1} \sim$ $B(1, \phi)$, where $\operatorname{Pr}\left(\tilde{\theta}_{i, t+1}=1\right)=1-\operatorname{Pr}\left(\tilde{\theta}_{i, t+1}=0\right)=\phi$ and $0 \leq \phi \leq 1$. Whether a firm will be hit by an extreme event is independent of the impact conditional on the hit, i.e., $E\left(\tilde{g}_{i, t+1} \tilde{\theta}_{i, t+1}\right)=E\left(\tilde{g}_{i, t+1}\right) E\left(\tilde{\theta}_{i, t+1}\right) \cdot{ }^{15}$ The variance of the return is

$$
\operatorname{Var}_{t}\left(\tilde{R}_{i, t+1}\right)=b_{i}^{2}+\sigma_{i}^{2}+\sigma_{g, i}^{2} \phi+\mu_{g, i}^{2} \phi(1-\phi)
$$

where $\sigma_{g, i}^{2} \phi$ is the expected impact uncertainty and $\mu_{g, i}^{2} \phi(1-\phi)$ is the incidence uncertainty. ${ }^{16}$

While the expected impact uncertainty monotonically increases with $\phi$, the relationship between incidence uncertainty and $\phi$ is non-monotonic. Incidence uncertainty is highest when $\phi$ equals 0.5 .

In our empirical analysis, we use implied volatility (IV) backed out from option prices as a measure of the expected volatility of a firm's stock return and, thus, uncertainty, similar to Bloom (2009); Kelly, Pastor, and Veronesi (2016); Dew-Becker, Giglio, and Kelly (2021) and others. Option-implied variance captures the risk-neutral expected variance. Our theoretical framework models the true expected variance in equation (4). Option-implied variance is a function of the true expected variance and VRP, where the VRP can capture variance risk premia or mispricing (see, for example, Bollerslev, Tauchen, and Zhou (2009); Lochstoer and Muir (2022)). While we abstract from VRP in this simple framework, we investigate the empirical effects of extreme weather events on VRP in Section 4.2. The predominant focus of our analyses is the extreme weather uncertainty after hurricane landfall (after the extreme weather event has occured), which captures impact uncertainty. In Section 4.5, we also analyze the uncertainty before hurricane landfall (before the extreme weather occurs) by looking at forecasts for individual hurricanes and hurricane seasons. Through these forecasts, we obtain probabilities of firm exposure to a hurricane, which proxy for $\phi$.

\footnotetext{
${ }^{15}$ Intuitively, firm $i$ 's expected return conditional on being hit or not is, respectively, $E_{t}\left(\tilde{R}_{i, t+1} \mid \theta=1\right)=$ $\bar{R}_{i}+\mu_{g, i}$ and $E_{t}\left(\tilde{R}_{i, t+1} \mid \theta=0\right)=\bar{R}_{i}$. The variance of the firm's returns conditional on being hit or not is, respectively, $\operatorname{Var}_{t}\left(\tilde{R}_{i, t+1} \mid \theta=1\right)=b_{i}^{2}+\sigma_{i}^{2}+\sigma_{g, i}^{2}$ and $\operatorname{Var}_{t}\left(\tilde{R}_{i, t+1} \mid \theta=0\right)=b_{i}^{2}+\sigma_{i}^{2}$.

${ }^{16}$ This is obtained by $\operatorname{Var}_{t}\left(\tilde{g}_{i, t+1} \tilde{\theta}_{i, t+1}\right)=E_{t}\left(\tilde{g}_{i, t+1}^{2} \tilde{\theta}_{i, t+1}^{2}\right)-\left(E_{t}\left(\tilde{g}_{i, t+1} \tilde{\theta}_{i, t+1}\right)\right)^{2}=E_{t}\left(\tilde{g}_{i, t+1}^{2}\right) E_{t}\left(\tilde{\theta}_{i, t+1}^{2}\right)-$ $\left(E_{t}\left(\tilde{g}_{i, t+1}\right)\right)^{2}\left(E_{t}\left(\tilde{\theta}_{i, t+1}\right)\right)^{2}$, where $E_{t}\left(\tilde{g}_{i, t+1}^{2}\right) E_{t}\left(\tilde{\theta}_{i, t+1}^{2}\right)=\left[\operatorname{Var}_{t}\left(\tilde{g}_{i, t+1}\right)+\left(E_{t}\left(\tilde{g}_{i, t+1}\right)\right)^{2}\right]\left[\operatorname{Var}_{t}\left(\tilde{\theta}_{i, t+1}\right)+\right.$ $\left.\left(E_{t}\left(\tilde{\theta}_{i, t+1}\right)\right)^{2}\right]=\mu_{g, i}^{2} \phi+\sigma_{g, i}^{2} \phi$.
} 
Predicting at the time of an event which firms will be most affected can be challenging due to different factors. Knowing ex ante which areas will actually flood in a particular storm, the extent and duration of power outages, whether a levy will break, or how long infrastructure repairs will take, can be challenging if not impossible. On the other hand, firms could be insured against extreme weather events or move establishments to locations that are less likely to be affected, particularly if firm operations are vulnerable to extreme weather events. Thus, whether extreme weather uncertainty is substantial or not is ultimately an empirical question.

\subsection{Firm exposure to hurricanes}

We determine firm exposure to hurricane landfall in two steps. First, we determine which counties are in the landfall region of a hurricane. Second, we calculate the share of a firm's establishments located in these counties. This share is our continuous measure of treatment intensity for each firm and each hurricane. Figure 4 Panel A shows a stylized example of this approach to measuring a firm's exposure to a landfall region.

In basing our firm exposure measure on the share of establishments in hurricane landfall regions, we place equal weight on different types of establishments that could potentially be important to firms. For example, while a store location that generates sales could be important for one firm, an establishment that is a factory without any direct sales could be crucial to another. We show robustness to using an alternative measure of landfall region exposure using establishment-level sales data from NETS in the Internet Appendix.

We define a county $c$ to be in the set $L_{R, h}$ of counties in the landfall region if the county centroid lies inside a radius $R$ of the eye of the storm. The radius accounts for the fact that through wind, rain, and storm surge, hurricanes can impact counties not located in

immediate proximity to the eye of the storm. Furthermore, using the location of the eye of a storm to determine a hurricane's landfall region has the distinct advantage that these data are available to investors in real time during a hurricane strike. The radius around the eye of the hurricane that we use for the main part of our analysis is 200 miles. Based on reanalysis data for hurricanes, which are released by NOAA anywhere from weeks to months after hurricanes have occurred, we find that the average outer border of a hurricane storm system - the area where wind speeds are at least 34KT - is 219 miles from the eye of the 
storm. ${ }^{17}$ We also consider smaller radii closer to the nucleus of the hurricane. Further, in the Internet Appendix, we present results when using reanalysis-based radii for individual hurricanes. These radii, which are released weeks to months after landfall and available starting in 2004, yield qualitatively similar results.

In the second step, we calculate the share of firm $i$ 's establishments in counties located in the hurricane's landfall region. Firm $i$ 's exposure to the landfall region of hurricane $h$ is

$$
\text { LandfallRegionExposure } e_{i, R, h}=\sum_{c}\left(\text { FirmCountyExposure }_{i, c} \times I_{c \in L_{R, h}}\right) \text {, }
$$

where FirmCountyExposure ${ }_{i, c}$ is the share of firm $i$ 's establishments in county $c$ in the year hurricane $h$ hits, and $I_{c \in L_{R, h}}$ is an indicator equal to 1 if county $c$ is in the landfall region for hurricane $h$. A firm's exposure to a hurricane landfall region is thus a continuous variable ranging from 0 to 1 . With larger radii, the average intensity of impact on exposed firms decreases, but the number of firms with a meaningful share of establishments in the landfall region increases. This can be seen in Figure 4 Panel A, where a larger radius would translate to more counties being shaded and a larger share of a firm's establishments being within the landfall region. Table 2 Panel B also illustrates this point, showing that the number of firms with high LandfallRegionExposure ${ }_{i, R, h}$ increases as the landfall radius increases.

\subsection{Baseline uncertainty estimation strategy}

We employ a difference-in-differences framework to estimate the uncertainty dynamics surrounding hurricanes. We jointly estimate the treatment effect across all hurricanes, where each hurricane landfall yields a separate treatment. Treatment intensity varies due to the continuous nature of the hurricane landfall exposure variable defined in equation (5). Firms with zero exposure to a particular hurricane serve as the controls for that event. ${ }^{18}$ As illustrated in Figure 1, the set of exposed firms vary across different hurricanes because hurricanes can occur in different regions across the Atlantic and Gulf coasts. We follow the

\footnotetext{
${ }^{17}$ Although the 200-mile radius is slightly lower than this empirical measure, in practice the two measures align well because we include a county in the landfall region if the landfall region includes the county centroid but not necessarily all of the county.

${ }^{18}$ We exclude firms that have been hit by a hurricane from the control set of other hurricanes that occur within 180 calendar days to avoid distortions due to overlapping. For this purpose, we deem a firm "hit" if the landfall region exposure is at least 0.25 . Varying this threshold leads to qualitatively similar results.
} 
recommendation of Bertrand, Duflo, and Mullainathan (2004) by collapsing the time series information into a pre- and post-treatment period for each difference-in-differences, that is, each hurricane. Figure 4 Panel B illustrates the hurricane timeline, with $T_{0}^{h}-1$ marking the pre-treatment period as the last trading day before hurricane inception, which occurs up to two weeks before landfall. ${ }^{19}$

We estimate uncertainty at hurricane landfall using the following firm-hurricane panel regression model, where each hurricane enters the regression as a separate time period:

$$
\log \left(\frac{I V_{i, T_{L}^{h}+\tau}}{I V_{i, T_{0}^{h}-1}}\right)=\lambda_{L, R, \tau} \text { LandfallRegionExposure } e_{i, R, h}+\pi_{h}+\psi_{\text {Ind }}+\epsilon_{i, h, \tau} .
$$

The dependent variable is the change in implied volatility from the day before inception $\left(T_{0}^{h}-1\right)$ to $\tau$ trading days after landfall $\left(T_{L}^{h}+\tau\right)$. We include hurricane fixed effects $\left(\pi_{h}\right)$, which is equivalent to including time fixed effects because each hurricane enters the regression as a separate time period. This fixed effect parametrically accounts for correlation of errors across firms within a time period (Petersen, 2009). We include industry fixed effects $\left(\psi_{\text {Ind }}\right)$ based on SIC classifications either by themselves or interacted with the hurricane (time) fixed effects to absorb industry-wide shocks. Given that the hurricane shock is measured at the county level, we cluster standard errors by county, assigning each firm to the county of its largest establishment share. ${ }^{20}$

Shortly after landfall, investors know that the hurricane has made landfall and where it has landed. But they do not necessarily know what the eventual impact on exposed firms will be. Thus, incidence uncertainty has been largely resolved, and we interpret the implied volatilities as of five or more trading days after landfall as reflecting impact uncertainty. While a hurricane can move further inland after landfall, by five days post landfall, the storm has either dissipated or is no longer a hurricane. Therefore, we interpret a positive and significant $\lambda_{L, R, \tau}$ to reflect impact uncertainty in the aftermath of a hurricane.

\footnotetext{
${ }^{19}$ The inception day of a hurricane is defined as the first day that NOAA publicizes a wind speed probability forecast advisory that, with at least 1 percent probability, the hurricane will ultimately make landfall. For hurricanes before 2007, we do not have these forecast advisories available and choose as inception day the first day that the hurricane appeared as a tropical depression.

${ }^{20}$ Our results are robust to alternate clustering choices including clustering by firm, county-hurricane (county-time), or by county after assigning each firm to the county of its headquarter location.
} 


\subsection{Accuracy of volatility expectations}

To test the efficiency of the volatility expectations derived from option prices, we define the volatility risk premium as the difference between the ex ante risk-neutral expectation and ex post realization of return volatility and examine how this spread varies relative to controls as a firm is exposed to a hurricane. We use $I V_{i, t, M}$ as the measure for the ex ante risk-neutral expected value of the future stock return volatility of firm $i$ between time $t$ and $M$. Our results are robust to using model-based or model-free $I V_{i, t, M}$. Details on the $I V_{i, t, M}$ measure are presented in Section 2.3. We use the annualized standard deviation of the underlying stock's daily returns over the remaining life of the option, between $t$ and $M$, as the measure of realized volatility $R V_{i, t, M} \cdot V R P_{i, t}$ is defined as

$$
V R P_{i, t}=V R P_{i, t, M}=I V_{i, t, M}-R V_{i, t, M}
$$

This definition of VRP captures the difference between ex ante market expectations of future volatility over a period and the ex post realized volatility over the same period, not a lagged or predicted measure of realized volatility. This is important because we use our VRP measure to analyze how efficiently investors price the uncertainty associated with hurricanes. Lochstoer and Muir (2022) use a similar definition when testing the accuracy of volatility expectations. Kelly, Pastor, and Veronesi (2016) and others also define VRP similarly. ${ }^{21}$

To analyze the effect of hurricane landfall on VRP, we estimate the regression:

$$
\overline{V R P}_{i, T_{L}^{h}+\tau}=\lambda_{L, R, \tau}^{V R P} \text { LandfallRegionExposure } e_{i, R, h}+\pi_{h}+\Psi_{i}+\epsilon_{i, h, \tau} .
$$

The dependent variable is VRP averaged from landfall to $\tau$ trading days after landfall. $\Psi_{i}$ is a firm fixed effect that absorbs differences unrelated to hurricanes in the VRP levels across firms. ${ }^{22}$ A negative estimate of $\lambda_{L, R, \tau}^{V R P}$ means there is a decline in VRP and is consistent

\footnotetext{
${ }^{21}$ For instance, Kelly, Pastor, and Veronesi (2016) define the variance risk premium as $E_{t}^{\mathbb{Q}}\left[R V_{i, t, M}^{2}\right]-$ $E_{t}^{\mathbb{P}}\left[R V_{i, t, M}^{2}\right]=I V_{i, t, M}^{2}-R V_{i, t, M}^{2}$ because the realized variance over the remaining life of the option, $R V_{i, t, M}^{2}$, is an unbiased estimate of the expected variance over the remaining life of the option. Instead of variance risk premia, we use volatility risk premia in our empirical analysis for its intuitive interpretation, as in Della Corte, Ramadorai, and Sarno (2016).

${ }^{22}$ Unlike with the implied volatility regression (6), it is not possible subtract the pre-inception value of the dependent variable in these VRP regressions because the realized volatility over the remaining life of an option calculated on the pre-inception date, $R V_{i, T_{0}^{h}-1, M}$, will include the impact of the hurricane. Including a firm fixed effect instead effectively allows for the estimation of deviations from a firm's mean VRP.
} 
with investor underreaction. This would represent a systematic bias in option prices for hurricane-exposed firms compared to unexposed control firms.

\section{Results}

\subsection{Uncertainty after landfall}

We begin by estimating the firm-level uncertainty generated by an extreme weather event post landfall. In Table 3, we present results from estimating equation (6) for 1 week (5 trading days) and 1 month (20 trading days) after landfall. We show results from regressions for which the landfall region is based on a 200-mile radius around the hurricane eye in Panel A. In Panels B and C, the radius is set to 100 and 50 miles, respectively. The number of observations decreases for radii below 200 miles in Panels B and C because the firms that have exposure to the 200-mile landfall region but not to the 100- and 50- mile landfall regions are dropped from the control set.

Table 3 Panel A shows that for the 200-mile radius, the $\lambda_{L, R, \tau}$ estimates go up to close to 8 percent, and are positive and significant across all specifications. In Panels $\mathrm{B}$ and $\mathrm{C}$, the estimates go up to 9 and 18 percent, respectively, when exposure is based on smaller radii and the treated establishments have thus been on average hit more intensely. This implies that relative to its pre-inception IV level, a firm with 100 percent of its establishments within 50 miles of landfall will see its implied volatility increase by about 18 percent. These are substantial magnitudes for impact uncertainty. These results indicate that firms with establishments located closer to the epicenter of the storm face more impact uncertainty. The coefficient estimates are higher one month after landfall than one week after landfall, which could stem from slow diffusion of information or investor inattention.

In Figure 5 Panel A, each point shows the coefficient estimate from a separate regression estimating equation (6) for $\tau$ trading days after landfall, showing how the effect on exposed firms' implied volatilities evolve over the 120 trading days (about 6 months) after landfall. As in Table 3, the coefficient estimate increases until about 1 month post-landfall, at which point it reaches close to 8 percent. From around 30 trading days, the implied volatility effect gradually decreases but remains significantly elevated for just over 3 months.

The length of time we observe persistence of uncertainty post landfall in our regression 
analysis is similar to the length of time we observe discussions of hurricane impacts in transcripts of calls between analysts and managers of hit firms. Figure 5 Panel B shows that the frequency of analyst call discussions of hurricanes per call increase sharply after hurricane landfall for hit firms relative to control firms. Discussion levels then remain elevated for some time before dropping sharply around 3 months post-landfall.

Volatility has been widely documented to exhibit persistence, first by Mandelbrot (1963) and Fama (1965), forming the basis for the vast literature on autoregressive conditional heteroskedasticity models from Engle (1982), Bollerslev (1986), and onwards. However, the literature knows much less about the economic mechanisms explaining why volatility is persistent. It is challenging to identify exogenous shocks that affect the volatility of a treated group but not a control group that would allow for an investigation into the origins of volatility persistence. For example, macroeconomic announcements affect the volatility of all firms and are found to only have short-lasting effects. ${ }^{23}$ By using extreme weather events as shocks to volatility, we are able to examine exogenous events that affect the volatility of a set of hit firms but not a set of control firms. Our results show that the increase in implied volatility is long-lasting, and that discussions of hurricanes in analyst calls are similarly persistent. These results suggest that learning about how a firm is impacted by a specific event takes time, and this constitutes an important driver of volatility persistence.

To further assess the economic significance of these estimates, we use our regression coefficient estimates to compute how much hedging costs increase in the aftermath of a hurricane for investors of firms with exposure to the landfall region, if, hypothetically, investors were to hedge 100 percent of the equity of exposed firms. The higher the implied volatility of an option, all else equal, the higher the option premium, reflecting increased costs of hedging. After hurricane landfall, the total additional cost of hedging the impact uncertainty over our sample period would have been as high as 93 billion U.S. dollars in 2019 inflation-adjusted terms. ${ }^{24}$ This magnitude is considerable, representing up to 14 percent of the $\$ 659$ billion in

\footnotetext{
${ }^{23}$ See, for example, Ederington and Lee (1993) and Andersen and Bollerslev (1998). Andersen and Bollerslev (1998) write on page 223: "The origin of longer run volatility persistence remains an important topic for future research." Further, they write on page 234: "Announcements may thus constitute news arrivals with a well-defined content and clear-cut termination that endows them with a particularly short-lived impact, largely unrelated to the strong volatility persistence observed at the daily level."

${ }^{24}$ These values are based on IV change coefficient estimates for the landfall region based on a 200-mile radius around the eye of the storm, as shown in Table 3, of 7.581 for 20 trading days post landfall. The IV, landfall region exposure, vega, and number of shares outstanding of exposed firms are used for the
} 
total hurricane damages estimated by NOAA for the same time period as shown in Table 1.

These large estimates of uncertainty raise the question of why firms do not eliminate this uncertainty through relocation or other adaptations. In the absence of constraints, vulnerable firms, for example, could relocate away from areas with hurricane risk, leaving only the most resilient firms in high risk areas. This would reduce the extent of extreme weather uncertainty observable for hit firms. However, in practice, there are constraints on relocation. First, similar to other adaptations, relocation itself is costly. Second, many firms locate near population centers due to customer demand and labor supply. In the United States, population centers are often located along the coast where hurricane risk is largest, as shown in Figure 2. High costs, myopia, and agency problems are potential factors that prevent firms from relocating or making other adaptation investments.

Further, firms could potentially reduce uncertainty by insuring themselves against extreme weather events. However, firms may not be well-insured because, like relocation, it is costly. Firms that are willing to spend on insurance may not be able to fully insure against the impacts of extreme weather events. Even when insurance against property damage and business interruption is available, such insurance generally does not provide coverage against impacts of hurricanes on general demand or labor supply in a local economy. ${ }^{25}$ In the case where firms are insured, uncertainty can arise about whether coverage is adequate and about potential delays or disputes regarding payouts. We discuss this further in Section 4.3.

Finally, we find that some firms are positively affected by hurricanes while others are negatively affected, as we discuss in Section 5.4. The increase in volatility is not driven by only negative news. The firm may have incentives to communicate such positive impacts quickly and reduce uncertainty. However, these positive impacts, like negative impacts, might not be immediately discernible. For example, positive sales from rebuilding activity could accrue slowly. Also, firm management might be reluctant to attribute positive performance to an extreme weather event over which they had little control.

\footnotetext{
computation.

${ }^{25}$ Further, insurance companies have been shown to move out of areas that they deem too risky and costly to insure given regulatory constraints and other frictions. The New York Times writes in July 2021: "And it adds to growing concern among economists about a new issue in the climate crisis: whether some parts of the United States are becoming too risky to insure, at least at a cost that most people can afford."
} 


\subsection{Do investors underreact to extreme weather uncertainty?}

The results in the previous sections show that investors price in substantial uncertainty after a hurricane makes landfall. A question that naturally follows is how this increase in expected volatility priced in option markets compares to the subsequent realized volatility for hurricane-hit firms. Do option markets efficiently price the effects of extreme weather on volatility or is there evidence of underreaction?

Table 4 reports the results of the regression specification in equation (8), which compares ex ante market expectations of future volatility with ex post realized volatility for a firm. The coefficient estimate captures the change in this spread due to hurricane exposure. The table shows the effects of hurricanes on average VRP over several time frames post landfall. In line with investors underreacting to hurricanes, one week post-landfall, the coefficient estimates are consistently negative and significant. Panel B shows that the underreaction is particularly strong for firms with establishments within 50 miles of the eye of a hurricane - a firm with all its establishments within that landfall region experiences up to 21 percentage points lower VRPs, compared to control firms with no exposure to the hurricane.

In both panels, the underreaction becomes smaller as the horizon post-landfall extends, suggesting that the underreaction reverts over time in a similar manner as the IV shown in Figure 5. However, even a month after landfall, the underreaction remains severe.

Other research in the volatility literature finds that investors fail to update expectations based on immediately-preceding realized volatility (Cheng, 2019; Lochstoer and Muir, 2022), and that investors underreact to the information contained in past realized volatility. However, this is a separate mechanism from the underreaction we document. Because a hurricane is a specific exogenous event, the underreaction is not caused by investors incorrectly updating their expectations based on the realized volatility over preceding months. The investors correctly anticipate that the hurricane will lead to higher realized volatility, but they underestimate by how much.

Because we analyze hurricanes, and thus, a series of well-identified shocks that cause changes in firm-level volatility expectations, we can test if there is learning with regard to these shocks. While these results imply that investors underestimate hurricane impacts on return volatility, it is possible that this underreaction has diminished over time if investors have learned to price extreme weather events more efficiently. Particularly, one could imagine that after a salient hurricane this underreaction diminishes for subsequent hurricanes. 
In our sample, the hurricane most likely to have had such an effect is Hurricane Sandy, which made landfall in the New Jersey and New York area in 2012. Not only was Sandy very damaging as reported in Table 1, but it also hit an area that had previously been largely spared from head-on hits by hurricanes. Further, New York City is the financial center of the US. In fact, the New York Stock Exchange was closed for two days because of Sandy. New York City and surrounding states like Connecticut and New Jersey that were also affected by Sandy are home to a large share of mutual funds and hedge funds in the United States. Research has shown that personal experiences can make investors more attuned to risks. For example, Malmendier and Nagel (2016) show that personal inflation experiences matter for inflation expectations and Alekseev, Giglio, Maingi, Selgrad, and Stroebel (2022) find that mutual fund managers' trading reacts to local temperature shocks, reflecting a change in climate change beliefs. Therefore, the experience of Hurricane Sandy may have made these investors more aware of extreme weather risks and correspondingly, increased pricing efficiency through the capital they manage. ${ }^{26}$

We test whether the negative VRP effect diminished after Hurricane Sandy by estimating the regression in equation (8) with an additional term that interacts the landfall exposure variable with a PostSandy indicator that equals one for hurricanes from 2013 onwards. We report the results for 1 week, 1 month, and 2 months (5, 20, and 40 trading days) post landfall in Table 5. The coefficient estimates on the interaction term are always positive and for the majority of the specifications significant. The coefficients are also economically large, canceling out the negative coefficient estimate on the uninteracted LandfallRegionExposure term in several specifications at longer time horizons.

In Figure 6, we show how long it takes for the negative VRP effect due to landfall exposure to revert back to zero, that is, for the underreaction to resolve. The figure depicts the estimates of $\lambda_{L, R, \tau}^{V R P}$ in equation (8) with VRP averaged over five-trading-day increments post landfall. In Panel A, we see that before Hurricane Sandy, the underreaction persisted for about one-and-a-half months (30 trading days). Panel B shows that after Hurricane Sandy, the VRP was generally not distinguishable from zero. In fact, we estimate a positive change in VRP around 20 to 30 trading days, indicating that option markets price in a premium.

\footnotetext{
${ }^{26}$ The most damaging and arguably most prominent hurricane before Sandy was Hurricane Katrina, which made landfall in Louisiana in 2005. Katrina was unlikely to have the same impact on asset managers as Sandy. We do not find an improvement in pricing efficiency post Katrina.
} 
These results suggest that option markets have started to price extreme weather uncertainty more efficiently. However, it took a particularly salient event for efficiency to improve. This finding calls into question whether financial markets will be attentive and react quickly to efficiently price extreme weather events that are novel in terms of intensity or location due to climate change.

Internet Appendix Section C.3 presents the returns to a trading strategy that takes on the implied volatility exposure using delta-neutral straddles at landfall for firms hit by hurricanes against the returns to the same strategy for control firms that are not exposed. The results are consistent with an underestimation in option prices to the uncertainty generated for firms from hurricane landfall.

\subsection{Real channels of extreme weather uncertainty}

Having established that hurricanes cause significant uncertainty for firms, we now investigate the real economic channels underlying firm impacts. We apply natural language processing tools to Refinitiv analyst call transcript data to first document the economic channels driving uncertainty and then provide insights into which channels are associated with greater pricing inefficiencies. Both analyses contribute to the ongoing discussion of companies' climate risk disclosures in academic research (see, for example, Sautner, van Lent, Vilkov, and Zhang (2022a)) and regulatory circles (see, for example, the rule proposed in 2022 on climate-related disclosures by the Securities and Exchange Commission).

Analyst call transcript data data have been used in the literature to examine firm-level uncertainty (see Hassan, Hollander, Van Lent, and Tahoun (2019)) and to develop firm climate change exposure measures (see Sautner, van Lent, Vilkov, and Zhang (2022a) and Sautner, van Lent, Vilkov, and Zhang (2022b)). Whereas those papers use discussions in analyst call transcripts to determine which firms are exposed to political and climate risks that are otherwise difficult to observe, we identify firm exposure to specific exogenous events based on establishment locations and hurricane regions that we observe directly. This

focus on specific events and affected firms allows us to identify the real channels driving the uncertainty and underreaction that we document in previous sections. Analyst call discussion of a particular channel in relation to a hurricane occurs when the impact of that channel on the firm's performance is likely material but not obvious, and thus warrants a discussion 
between analysts and firm management.

In this analysis, we examine transcripts of calls between analysts and firm management of hit firms occurring within 180 calendar days (6 months) of hurricane landfall. We focus on "hurricane paragraphs," that is, analyst call paragraphs that contain some form of the terms, "hurricane" or "tropical storm." We identify five distinct real channels: business interruption, physical damages, insurance, supply, and demand. For each channel, we set a paragraphlevel indicator equal to 1 if a hurricane paragraph contains a term assigned to the channel in our dictionary. The dictionary is shown in Internet Appendix Table C.1. We develop this dictionary by carefully examining a random five percent sample of hurricane paragraphs and applying judgment to balance Type I and Type II errors. We validate this methodology by performing a Latent Dirichlet Allocation analysis of all hurricane paragraphs, which confirms that we are not missing any major channels through our manual inspection. More details on the data processing and methodology are given in the Internet Appendix.

Table 6 presents results from regressing the frequency of discussion of hurricanes and real channels on our continuous LandfallRegionExposure variable defined in equation (5). Column 1 shows that the number of hurricane paragraphs increases significantly with landfall exposure. The coefficient estimate implies that a firm with all of its establishments located in a hurricane landfall region discusses hurricanes across five more paragraphs than a control firm on average. This substantial magnitude validates our LandfallRegionExposure as a predictor of uncertainty because it predicts not only large increases in implied volatility but also discussions regarding hurricanes between analysts and firm management.

Columns 2 to 6 examine the real channels that are discussed in the context of the hurricanes. Landfall exposure increases discussion of business interruption, physical damages, insurance, and demand in hurricane paragraphs. ${ }^{27}$ Physical damages and business interruption appear to be dominant channels for hurricane impacts, as they show the largest increase in the frequency with which they are discussed in response to hurricane exposure. The coefficient estimates on insurance and demand are smaller but still strongly significant. The significant coefficient on insurance suggests that, in practice, the degree to which a firm is insured is unclear. Analysts and investors might not have any information on the

\footnotetext{
${ }^{27}$ We restrict the sample in columns 2 to 6 to the firm-storm observations for which hurricanes are mentioned at least once to ensure that we are not simply measuring again the fact that hurricanes are being mentioned. This also ensures that we only count the discussion of a specific channel if hurricane terms are also mentioned.
} 
firms' insurance coverage or managers may be uncertain about insurance payouts due to slow processing of claims. The significant increase in discussion around demand suggests that there is uncertainty about how the hurricane affects demand for the firm's products. Indeed, when inspecting discussions around demand, we find that hurricanes can lead to not only decreases in demand but also increases. ${ }^{28}$ Supply is the only channel that does not respond significantly to landfall region exposure. This could be explained by suppliers of hit firms frequently being located out of the paths of hurricanes and thus unaffected. On the whole, the results in Table 6 demonstrate that potential impacts of hurricanes on firms can be complex and involve multiple real channels.

In Table 7, we present results from regressing VRP on the discussion frequency of each of the five channels interacted with landfall exposure. The results indicate that market underreactions increase with discussion of business interruption, physical damages, demand, and supply. The supply channel generates the strongest investor underreaction, consistent with the prior literature showing investors are inattentive to shocks to suppliers (see, for example, Menzly and Ozbas (2010)). Interestingly, investors do not underreact to the uncertainty generated through the insurance channel, suggesting that investors pay more attention and/or have a better understanding of the lack of insurance coverage or the extent of delays and disputes that can occur for firms dealing with insurance firms. Consistent with our findings in Section 4.2, the analysis of VRP post Sandy in Internet Appendix Table C.2 shows that the underreactions in response to the particular channels shown in Table 7 reversed after Hurricane Sandy.

Although prior work has shown that natural disaster shocks can have real effects by affecting firm sales and propagating through supply networks (see Barrot and Sauvagnat (2016a) and Pankratz and Schiller (2021)), our analysis is distinct, and to our knowledge, the first to examine the real channels through which firms are affected by extreme weather events based on their discussions with analysts and investors. First, we are able to identify multiple channels through which firms are affected by hurricanes as well as their relative importance.

\footnotetext{
${ }^{28}$ The calls include discussions of firms benefiting from hurricane-driven increases in demand for products like roofing, generators, and mosquito remediation. For example, Procter \& Gamble Co on November 4, 2003: "Another factor was the blackout and hurricane Isabel. Obviously, both were bad news for a lot of people but for Duracell, they created a surge in battery buying." American Vanguard Corp on November 2, 2017: “...we recorded strong sales of Dibrom, our mosquito adulticide, as domestic customers responded to FEMA's requirement for aerial spraying of about 6 million acres over coastal Texas and Florida in the aftermath of Hurricanes Harvey and Irma."
} 
Further, by combining the text data with financial market data, we develop new insights on which channels lead to investor underreaction. Taken together, our findings are directly relevant to the SEC's March 2022 Proposed Rules to Enhance and Standardize ClimateRelated Disclosure for Investors, which "would require a registrant to disclose information about... governance of climate-related risks and relevant risk management processes" and "the impact of climate-related events (severe weather events and other natural conditions) ... on the line items of a registrant's consolidated financial statements." ${ }^{29}$ In particular, our results indicate that requiring disclosures about firms' business continuity plans, resilience or vulnerability of physical structures, insurance coverage, and supply and demand exposures to extreme weather events could be of significant value to investors.

\subsection{Extreme weather uncertainty and discount rates}

Our results in the previous sections show that hurricanes cause a significant increase in uncertainty for exposed firms. Because hurricanes are local and do not affect the general US economy (Strobl, 2011), each hurricane can be considered an exogenous, idiosyncratic shock. In a standard CAPM world, such shocks would be diversifiable and would not affect the discount rate of the representative investor. However, some theories that model the case where investors are not perfectly diversified due to segmented markets or other frictions, predict instead that when there is underdiversification, shocks to expected idiosyncratic volatility affect expected returns (see, for example, Levy (1978); Merton (1987)). Merton (1987) argues that this lack of diversification, which has been established empirically (see, for example, Polkovnichenko (2005) and Goetzmann and Kumar (2008)), can stem from investors only investing in securities that they know about, which leads to segmented markets. An example of this is the home bias documented by Coval and Moskowitz (1999). In Internet Appendix A, we show with a simple extension of the Merton (1987) model how extreme weather uncertainty can affect expected returns. Here, we use our difference-in-differences setting, which exploits exogenous extreme weather events, to estimate the effects of changes in idiosyncratic volatility on expected returns.

\footnotetext{
${ }^{29}$ See "SEC Proposes Rules to Enhance and Standardize Climate-Related Disclosures for Investors" available at https://www.sec.gov/news/press-release/2022-46.
} 


\subsubsection{Cash flow and discount rate decomposition}

We first test if price changes of stocks hit by hurricanes are driven by discount rate or cash flow news. For this purpose, we adapt the framework of Chen, Da, and Zhao (2013), which uses earnings forecasts and the corresponding implied cost of capital (ICC) to decompose price changes into discount rate and cash flow news. This framework has the advantage of allowing decomposition without resorting to stock return predictability (see, for example, Campbell and Shiller (1988) and Vuolteenaho (2002)). Stock return predictability is generally found at longer horizons, but Chen, Da, and Zhao (2013) can use their framework at horizons as short as a quarter. This allows us to isolate in time the impact of a hurricane.

The ICC is the value of $q$ that solves the standard present value of future dividends formula:

$$
P_{i, t}=\sum_{k=1}^{15} \frac{F E_{i, t+k}\left(1-b_{i, t+k}\right)}{\left(1+q_{i, t}\right)^{k}}+\frac{F E_{i, t+16}}{q_{i, t}\left(1+q_{i, t}\right)^{15}}=f\left(c_{i, t}, q_{i, t}\right),
$$

where $P_{i, t}$ is the stock price of firm $i$ on day $t, F E_{i, t+k}$ is the $k$ years ahead consensus earnings per share (EPS) forecast, and $b_{i, t+k}$ is the plow back rate. We follow Pastor, Sinha, and Swaminathan (2008) and Chen, Da, and Zhao (2013) and consider forecasts up to a 16 year horizon and denote this series of earnings forecast as $c_{i, t}$.

As shown by Chen, Da, and Zhao (2013), the cash flow and discount rate components of the capital gain return, $\operatorname{Ret}_{i, t+l}=\left(P_{i, t+l}-P_{i, t}\right) / P_{i, t}$, are given by

$$
\begin{aligned}
C F_{i, t: t+l} & =\left(\frac{f\left(c_{i, t+l}, q_{i, t+l}\right)-f\left(c_{i, t}, q_{i, t+l}\right)}{P_{i, t}}+\frac{f\left(c_{i, t+l}, q_{i, t}\right)-f\left(c_{i, t}, q_{i, t}\right)}{P_{i, t}}\right) / 2 \\
D R_{i, t: t+l} & =\left(\frac{f\left(c_{i, t}, q_{i, t+l}\right)-f\left(c_{i, t}, q_{i, t}\right)}{P_{i, t}}+\frac{f\left(c_{i, t+l}, q_{i, t+l}\right)-f\left(c_{i, t+l}, q_{i, t}\right)}{P_{i, t}}\right) / 2,
\end{aligned}
$$

where we set $l$ to be either a quarter or half year. The discount rate and cash flow news of the capital gain return are then obtained as

$$
\begin{aligned}
\operatorname{Var}\left(\operatorname{Ret}_{i, t: t+l}\right) & =\operatorname{Cov}\left(C F_{i, t: t+l}, \operatorname{Ret}_{i, t: t+l}\right)+\operatorname{Cov}\left(\operatorname{DR}_{i, t: t+l}, \operatorname{Ret}_{i, t: t+l}\right) \\
1 & =\frac{\operatorname{Cov}\left(\operatorname{CF}_{i, t: t+l}, \operatorname{Ret}_{i, t: t+l}\right)}{\operatorname{Var}\left(\operatorname{Ret}_{i, t: t+l}\right)}+\frac{\operatorname{Cov}\left(\operatorname{DR}_{i, t: t+l}, \operatorname{Ret}_{i, t: t+l}\right)}{\operatorname{Var}\left(\operatorname{Ret}_{i, t: t+j}\right)}
\end{aligned}
$$

where the two terms in equation (13) are the slope coefficients of regressing the cash flow and discount rate components on the capital gain return. Importantly, the variance of the 
capital gain return differs from the IV used earlier in the analysis. While the IV provides an expectation of daily return variation, the EPS forecasts used here are not updated daily. As this makes it impossible to decompose the returns at a daily frequency, we measure the variance of the capital gain return at a quarterly or longer frequency. Recall that we document in Figure 5 Panels A and B that the uncertainty effects and analyst call discussions associated with a hurricane are long-lasting. As such, it is reasonable to expect to still observe return effects of a hurricane by the end of the quarter in which it makes landfall.

To estimate whether the share of variance driven by cash flow (as opposed to discount rate) news differs significantly between firms that are hit by a hurricane and firms that are not, we split firm-quarter observations into two samples. The first sample contains all firmquarter observations for firms hit by a hurricane in a given quarter, where we designate as hit the firms with at least 25 percent of their establishments in the hurricane landfall region. The second sample contains the remaining control firm-quarter observations. We estimate a pooled regression for each of the two samples with $C F_{i, t: t+l}$ and $D R_{i, t: t+l}$ being the dependent variables, respectively, and $\operatorname{Ret} x_{i, t: t+l}$ being the independent variable. ${ }^{30}$ By construction, the cash flow and discount rate news components add up to one in this variance decomposition.

Table 8 presents the results for hit and control firms at quarterly and semi-annual horizons. The results confirm that the return variance is higher for hit firms than control firms in all four specifications. We show the difference between hit and control firms in their cash flow news shares and discount rate news shares, respectively, as well as the lower and upper 95 percent confidence bands of these differences. Our estimates of the discount rate and cash flow shares for the control firms are generally comparable to the estimates in Chen, Da, and Zhao (2013) for their analysis up to 2010, despite our use of a more recent sample period. We find that while the discount rate news dominates at the quarterly horizon, the role of cash flow news increases at the longer semi-annual horizon. However, in looking at the Hit-Control columns, we find that the share of discount rate and cash flow news in the variance decomposition for the hit firms is not significantly different from the control firms. This result suggests that the increase in variance after a hurricane hit are driven not only by impacts on firm cash flow, but also by changes in the rate at which the expected cash flows

\footnotetext{
${ }^{30} \mathrm{Chen}$, Da, and Zhao (2013) estimate the regression for each individual firm and then average across firms. This approach does not work in our setting because a firm is generally not hit in a sufficient number of quarters to allow for a time series regression on an individual firm.
} 
are discounted.

\subsubsection{Expected returns}

The results on the return decomposition suggest that despite being local and idiosyncratic, hurricane shocks affect discount rates as well as cash flows. The empirical evidence addressing whether idiosyncratic shocks to expected volatility are priced in stock returns has been mixed. For example, while Ang, Hodrick, Xing, and Zhang (2006, 2009) find that high idiosyncratic volatility predicts low stock returns, $\mathrm{Fu}$ (2009) comes to the opposite conclusion. Unlike these papers whose estimates of idiosyncratic volatility depend on a factor model that can be subject to misspecifications, our setting allows us to exploit an exogenous idiosyncratic shock to a stock's expected volatility in order to analyze if such a shock is priced in stock returns.

To analyze the compensation for idiosyncratic shocks to firm uncertainty caused by extreme weather events, we estimate a firm-hurricane panel regression model similar to our previous specifications. Here, the dependent variable is the cumulative abnormal return relative to the Fama-French five-factor model (Fama and French, 2015), but results are qualitatively similar when using excess returns (see Internet Appendix Table C.12.) We estimate the Fama-French five-factor model for each stock and hurricane based on 120 trading days (roughly half a calendar year) before the hurricane inception day. We next use the coefficient estimates from this first stage regression to compute for each firm and hurricane the cumulative abnormal returns earned during a defined period that occurs after hurricane landfall. We use this cumulative abnormal return as our dependent variable in the following regression:

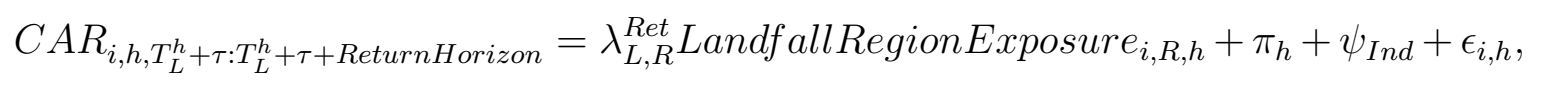

where LandfallRegionExposure $e_{i, R, h}$ serves as our proxy for firm uncertainty caused by hurricane landfall. For our baseline specification, we set $T_{L}^{h}+\tau$, the starting point of the cumulative abnormal returns, to 30 trading days post landfall. This is when the IV peaks on average after increasing post hurricane landfall. However, the results are qualitatively similar for other values of $\tau$. We examine multiple return horizons, with ReturnHorizon equal to 20, 30, and 40 trading days, in line with the average expiry of options in our sample, which exceeds a month (see Table 2). 
If the uncertainty caused by a hurricane leads to higher abnormal returns, we would expect the estimate of $\lambda_{L, R}^{R e t}$ in equation (14) to be positive and significant. In the results shown in Table 9 Panel A, the coefficient estimates are insignificant for all specifications. These results are inconsistent with investors demanding a premium for holding stocks exposed to higher uncertainty due to hurricanes.

A potential explanation for this finding is that investors may fail to correctly price the uncertainty associated with a hurricane. In this case, even though hurricanes affect discount rates as we find in the variance decomposition analysis, the underestimation of the volatility of affected firms could yield noisy and insignificant return estimates because prices do not adjust sufficiently. We discuss this case more formally in the context of our theoretical framework in Internet Appendix A. Our findings in Section 4.2 show that after Hurricane Sandy, the implied volatilities of option prices of hit firms more accurately reflect future realized volatility. If investors price hurricanes more accurately in options markets later in the sample, we could then also see higher returns associated with hurricane strikes in equity markets.

We thus extend the regression model in equation (14) by adding a term that interacts our landfall region exposure variable with an indicator that equals one for hurricanes after Hurricane Sandy. We report the results in Table 9 Panel B. While the coefficient estimate on LandfallRegionExposure is mostly negative and significant for some specifications, the coefficient estimate on LandfallRegionExposure interacted with the post-Sandy indicator is always positive and significant. Interestingly, the magnitude of the coefficient estimate on the interacted term is substantially higher than the magnitude of the estimate on LandfallRegionExposure, suggesting that the net effect on abnormal returns is positive after Sandy. The estimate on the uninteracted variable predicts an effect on returns of around -1.5 percent, but the prediction from the estimate on the interacted variable ranges from 2.8 to 7.8 percent. These estimates are consistent with the hypothesis that an idiosyncratic shock to expected volatility will be compensated with higher expected returns.

\subsection{Uncertainty before landfall}

Our analysis has thus far focused on the uncertainty post landfall, that is, the impact uncertainty. As discussed in Section 3.1, investors might price in incidence uncertainty and 
expected impact uncertainty before an extreme weather event occurs. Pricing of extreme weather events before they occur is important due to concerns that sudden corrections of mispriced climate risks could pose a threat to financial stability (Carney, 2015).

Equation (4) shows that expected impact uncertainty and incidence uncertainty depend on the probability of the extreme weather event occurring. In this section, we examine how uncertainty reflected in option markets before landfall is related to the short-term, daily forecasts for a hurricane's path after its inception and the longer-term, annual hurricane season forecasts made by NOAA.

\subsubsection{Short-term forecasts of a hurricane path}

We use NOAA hurricane wind speed forecast text advisories to develop daily firm-specific exposures to hurricanes before landfall. As with our approach in Section 3.2, we first identify which counties are exposed to hurricane forecasts and then develop continuous firm exposure measures based on each firm's share of establishments in the exposed counties. This analysis includes more storms than our baseline post-landfall analyses because it includes storms that were forecast to possibly make landfall but that did not ultimately do so. A list of included storms is shown in Table 1 Panel B.

We identify counties exposed to the forecast path of a hurricane as follows. Since 2007, NOAA has issued intra-daily real-time wind speed probability text advisories in advance of potential hurricanes. We use the last forecast available before market close on each trading day because it contains the most updated predictions about the hurricane path, replacing any prior forecasts. It reflects the latest information available before end-of-day option prices are determined. Each file lists location-specific probabilities of hurricane-force winds. For a given probability threshold $P$, on each day, we develop the forecast region by identifying locations with reported probabilities of at least $P$, designating the counties for these locations as exposed to a hurricane forecast, and extrapolating this designation to nearby counties. As an example, Figure 3 illustrates the counties in the forecast region for a range of probability thresholds and days before landfall of Hurricane Sandy. Additional details on these data are in Internet Appendix Section B.2.

To estimate how hurricane forecast exposure affects uncertainty, we again use the last trading day before hurricane inception, $T_{0}^{h}-1$, as the pre-treatment period reference day. For post-treatment, we align observations by the number of days, $\Gamma$, before a storm makes 
landfall or dissipates, depicted in the identification strategy Figure 4 Panel B as $T_{L}^{h}-\Gamma$. Our regression estimates a variation of equation (6), where LandfallRegionExposure ${ }_{i, R, h}$ is replaced with ForecastExposure $_{i, P, h, \Gamma}$ :

$$
\log \left(\frac{I V_{i, T_{L}^{h}-\Gamma}}{I V_{i, T_{0}^{h}-1}}\right)=\lambda_{F, P, \Gamma} \text { ForecastExposure }_{i, P, T_{h}-\Gamma}+\pi_{h}+\psi_{\text {Ind }}+\epsilon_{i, h, \Gamma} .
$$

We estimate the regression separately for $\Gamma$ ranging from 1 to 5 days and probability thresholds $P$ from 1 to 50 percent, where each regression includes at least 5 storms.

Table 10 presents the results. Each column is from a separate regression performed for the specified $\Gamma$ and $P$. Because the location-specific NOAA wind speed probabilities rarely get high when a hurricane is far from the coast, the maximum probability threshold for which we can estimate our regression declines as the number of days to landfall or dissipation increases. The number of firms with a given exposure to the forecast path decreases as the probability threshold increases because, intuitively, the region covered by a higher probability is smaller. The results show that substantial uncertainty arises for firms in a hurricane forecast path. The estimates of $\lambda_{F, P, \Gamma}$ are always positive and statistically significant, regardless of whether time and industry fixed effects are included separately (Panel A) or interacted (Panel B). As modeled in our framework, for a given $\Gamma$, the magnitude of the coefficient estimate tends to increase with higher landfall probabilities, reaching up to 22 percent in the fifth column. This indicates that having all $100 \%$ of its establishments in the likely path of a hurricane can increase a firm's implied volatility up to 22 percent.

These empirical estimates confirm that uncertainty generally increases with landfall probability up to a point, as predicted in our theoretical framework. The results also indicate that investors pay attention to NOAA's hurricane forecasts, a finding that is not obvious given prior investigations showing investor inattention to other climatic events. For example, Hong, Li, and $\mathrm{Xu}$ (2019) show investor inattention to droughts, while studies on residential real estate pricing of sea level rise forecasts have yielded mixed results. ${ }^{31}$

\footnotetext{
${ }^{31}$ See, for example, Bernstein, Gustafson, and Lewis (2019); Giglio, Maggiori, Rao, Stroebel, and Weber (2021); Bakkensen and Barrage (2022); Baldauf, Garlappi, and Yannelis (2020); Murfin and Spiegel (2020).
} 


\subsubsection{Annual forecasts of a hurricane season}

Having established that investors price in significant uncertainty in response to short-term forecasts of potentially imminent hurricanes, a natural question that follows is whether investors also price in longer-term seasonal hurricane forecasts. NOAA releases seasonal outlooks every May for the hurricane season from June to November. Dating back to 2001, each annual seasonal outlook gives NOAA's estimated probability that the season will be above-normal, near-normal, or below-normal. ${ }^{32}$ In the Internet Appendix, we include a plot of these data. There is significant annual variation in these outlooks.

We test if options of firms with establishments in higher risk counties exhibit higher implied volatilities when NOAA forecasts a hurricane season with above-normal activity. For this analysis, we use options with 120 to 210 calendar days to expiry to span the majority of the hurricane season. We use two methods to measure a firm's exposure to hurricane season $s$. First, we compute the share of a firm's establishments in counties along the Atlantic and Gulf coasts, CoastalExposure $e_{i, s}$. Second, we select counties by their probability of being hit based on historical landfall regions and compute firm establishment shares in these counties, HistoricalHurricaneExposure ${ }_{i, s}$. Our regression specification is as follows:

$$
\begin{aligned}
\log \left(\frac{I V_{i, T_{0}^{s}+5}}{I V_{i, T_{0}^{s}-1}}\right)= & \lambda_{S, 1} \text { CoastalExposure }_{i, s} \times \text { AboveNormalSeasonProb }_{s} \\
& +\lambda_{S, 2} \text { CoastalExposure }_{i, s}+\pi_{s}+\psi_{\text {Ind }}+\epsilon_{i, s}
\end{aligned}
$$

where $T_{0}^{s}-1$ is the last trading day before NOAA's hurricane season outlook is announced in May, and $T_{0}^{s}+5$ occurs 5 trading days after the announcement. Varying the window length leads to qualitatively similar results. The variable AboveNormalSeasonProbs is the probability of an above-normal hurricane season. A positive estimate of $\lambda_{S, 1}$ would be consistent with investor attention to longer-term seasonal forecasts and imply heightened uncertainty if the probability of an above-normal season is high.

Table 11 presents the estimates using firm exposure to coastal counties in Panel A and to counties with a high historical probability of being hit in Panel B. None of the estimates of $\lambda_{S, 1}$ are statistically significant, and some point estimates are even negative. One potential explanation for this lack of investor response to seasonal forecasts is that the forecasts do not

\footnotetext{
${ }^{32}$ See, for example, National Weather Service "NOAA 2012 Atlantic Hurricane Season Outlook" https: //www.cpc.ncep.noaa.gov/products/outlooks/hurricane2012/May/hurricane.shtml.
} 
have sufficient predictive power for damaging hurricanes making landfall on the Atlantic and Gulf coasts in the upcoming season. In the Internet Appendix, we include a scatter plot that shows only a weakly positive relationship between the seasonal outlooks and the number of hurricanes making landfall in a given year. Another potential explanation is that investors do not pay attention to seasonal forecasts because those forecasts are longer term and lack the immediacy of specific hurricane path forecasts. While it is not feasible to distinguish between these two explanations with the available data, exploring investor reactions to shortand long-term forecasts of climatic risks is an interesting avenue for future research.

\section{$5 \quad$ Robustness and extensions}

\section{$5.1 \quad$ Industry effects}

One question that may arise is whether the uncertainty caused by hurricanes varies substantially across industries. To answer this question, we test whether our baseline post-landfall results are driven by a particular industry by adding an industry-specific interaction term to equation (6). The analyzed industries are construction, manufacturing, mining, retail, services, transportation, and wholesale based on the firms' SIC numbers, excluding agriculture and non-classified categories because of the small number of firms.

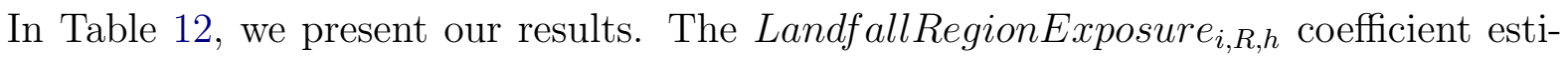
mates remain positive and significant in every industry specification, suggesting that our baseline results are not driven primarily by one sector. The estimate of the interaction term is insignificant for most specifications, suggesting limited industry-specific heterogeneity. Construction is the only industry for which the coefficient estimate on the interaction term is strongly significant and negative. The negative sum of the interacted and uninteracted coefficient estimates for the construction industry suggests that investors perceive lower uncertainty for construction firms due to hurricanes, which could reflect an expected boost in demand from rebuilding activity. Similarly, manufacturing firms might benefit from rebuilding activity. Manufacturing also has a negative coefficient estimate on the interaction term, but it is only weakly significant and the sum of the coefficients on the interacted and uninteracted variables is positive.

For mining, the interacted coefficient estimate is strongly significant and positive, indi- 
cating that these firms experience relatively more uncertainty after a hurricane hit. This is consistent with anecdotal evidence that Gulf Coast hurricanes can affect much of the oil and gas extraction sector. Further, mining firms are geographically bound to be close to natural resources, and thus they have less discretion over where to set up operations when trying to avoid hurricanes. Wholesale firms also have a significant and positive coefficient estimate. The relatively higher uncertainty for wholesale firms could be due to their operations being less diversified compared to, for example, a retail company. They have fewer but larger establishments and customer shipments.

\subsection{Firm selection}

A potential question about our empirical strategy is whether our results are driven by small firms. However, as reported in Table 2, relative to the total sample, the subsample of firms that had large exposure to a hurricane making landfall at least once, where we define large exposure as having an establishment share of at least 0.25 in a landfall region, has a comparable, if slightly higher, average market capitalization. Firms with coastal exposure can differ from other firms based on unobserved characteristics, but for a given hurricane event, we have coastal firms in both treated and control sets. A firm that is severely affected by one hurricane could have zero exposure to others. As such, selection on a set of coastal firms is unlikely to drive our results. Further, it is possible that firms that would be more vulnerable to hurricanes because of their particular line of business avoid being exposed to the Atlantic or Gulf Coasts. However, such sorting would bias us against finding evidence of large extreme weather uncertainty priced in option markets.

\subsection{Other types of extreme weather events}

In this paper, we have proposed a general framework and empirical approach for examining extreme weather uncertainty. In addition to our in-depth analysis of hurricanes, we test for external validity by examining whether investors price in higher uncertainty when firms are exposed to other types of extreme weather events, namely floods, snow storms, and tornadoes. The analysis is presented in Section C.2 of the Internet Appendix. For this analysis, we rely on FEMA disaster declarations to determine which counties have been hit and when each event began. 
We find evidence that implied volatilities rise in response to floods, snow storms, and tornadoes. The coefficient estimates and statistical significance are mostly lower than for hurricanes, which is likely due to these extreme weather events being less destructive and affecting a smaller number of firms. Interestingly, the uncertainty remains elevated for an extended period of time, much as it does for hurricanes. For all four extreme weather events the largest effects are found at least one month after the event occurred.

\subsection{Tail effects}

A question regarding the large estimates of extreme weather uncertainty that we address is whether investors are only concerned about downside risk, or if they anticipate that some firms may profit from the opportunity that a hurricane presents while other firms suffer losses. Some firms could, for example, benefit from rebuilding activity and an increase in demand for their products. Indeed, as discussed in Section 4.3, Refinitiv transcripts include discussions of firms benefiting from hurricane-driven increases in demand for products.

In Table C.5 of the Internet Appendix, we examine the cross-sectional dispersion of the cumulative abnormal and excess stock returns since hurricane inception of hit firms compared to control firms. ${ }^{33}$ We find a substantially larger dispersion of returns for hit firms than for control firms, which is consistent with the higher stock return volatility of hit firms. Notably, the dispersion is not only driven by the left tail of the distribution. While underperforming hit firms have lower cumulative returns than underperforming control firms, outperforming hit firms have higher cumulative returns than outperforming control firms.

\subsection{Insurance firms}

While we exclude financial firms from the analyses in this paper, we separately conduct a similar analysis on stock options of property and casualty insurance firms. The insurance statutory financials from S\&P Global Market Intelligence provide us with the share of total premiums in each state written by U.S. property and casualty insurance firms. We estimate the regression in equation (6) for these property and casualty insurance firms replacing the

\footnotetext{
${ }^{33}$ We analyze returns instead of option-based measures of tail risk like the IV slope because a large share of the firms in our sample do not have a sufficient number of liquid options with different strike prices to reliably compute the IV slope.
} 
independent variable with the share of total premiums, lagged by one year, written in states that experienced a given hurricane landfall. We find even larger estimates of extreme weather uncertainty for insurance firms than in our baseline results. The IV is estimated to increase by 70 percent for an insurance firm that receives all its premiums from hit states. Internet Appendix Section C.5 provides more details.

\section{Conclusion}

This paper fills a gap in the literature on the uncertainty faced by firms due to extreme weather. Extreme weather events constitute exogenous shocks because prevailing conditions of the firm do not affect the timing and likelihood of such events. Their impact regions are local and thus affect only a subset of firms in the economy, creating a unique experimental setting. We present a simple theoretical framework on extreme weather uncertainty. Through a well-identified empirical framework, we isolate and analyze extreme weather uncertainty.

We find that options of firms operating in regions affected by a hurricane have considerably higher implied volatility after the hurricane hit, implying substantial impact uncertainty. The elevated implied volatility returns to pre-hurricane levels only several months after landfall, indicating that the impact uncertainty resolves slowly. Mirroring this finding of significant and prolonged increases to uncertainty, a systematic textual analysis of the transcripts of calls between analysts and firm management reveals that discussions of hurricanes jump after landfall for hit firms and remain elevated for a prolonged time. Our results show that learning about how a firm is impacted by a specific event takes time, which can drive the observed volatility persistence.

A systematic analysis of discussions in transcripts of calls between analysts and firm managers reveals that there are multiple real channels through which hit firms are affected by hurricanes, including business interruption and physical damages as well as insurance, demand, and supply.

Despite these large increases in the expectations of volatility implied in option markets, we find that investors underestimate a hurricane's impact on the eventual realized return volatility of hit firms. After Hurricane Sandy in 2012 - which hit the financial center of the US in an unprecedented and highly damaging manner - the ex ante expectations of future volatility embedded in the option prices of hit firms are closer to the ex post realized volatility 
over the life of the option. This suggests that the informational efficiency of markets increased after many investors personally experienced a particularly salient event.

In a return variance decomposition using changes in the earnings per share forecasts of hit firms and control firms following hurricane strikes, we find evidence that these idiosyncratic shocks constitute both discount rate news and cash flows news. In line with this finding, after investors' expectations of extreme weather uncertainty become more accurate post-Sandy, the increase in expected idiosyncratic volatility due to hurricanes predicts higher returns.

Our results suggest that markets need time to learn how to price extreme weather events and are unlikely to efficiently price novel climatic risks stemming from climate change. Further, extreme weather events that are predicted to become more frequent and severe may not be diversified away by investors and could affect firms' cost of capital even if the events are local. One potential way to reduce uncertainty associated with extreme weather events and increase pricing efficiency could be to require better firm disclosures on potential vulnerabilities to extreme weather events and associated hedging and insurance decisions. 


\section{References}

Addoum, Jawad M., David Ng, and Ariel Ortiz-Bobea, 2020, Temperature shocks and establishment sales, Review of Financial Studies 33, 1331-1366.

Albuquerque, Rui, 2012, Skewness in stock returns: Reconciling the evidence on firm versus aggregate returns, Review of Financial Studies 25, 1630-1673.

Alekseev, Georgij, Stefano Giglio, Quinn Maingi, Julia Selgrad, and Johannes Stroebel, 2022, A quantity-based approach to constructing climate risk hedge portfolios, National Bureau of Economic Research Working Paper.

Alok, Shashwat, Nitin Kumar, and Russ Wermers, 2020, Do fund managers misestimate climatic disaster risk?, Review of Financial Studies 33, 1146-1183.

Amihud, Yakov, 2002, Illiquidity and stock returns: Cross-section and time-series effects, Journal of Financial Markets 5, 31-56.

Andersen, Torben G, and Tim Bollerslev, 1998, Deutsche mark-dollar volatility: intraday activity patterns, macroeconomic announcements, and longer run dependencies, the Journal of Finance 53, 219-265.

Andersson, Mats, Patrick Bolton, and Frederic Samama, 2016, Hedging climate risk, Financial Analysts Journal 72, 13-32.

Ang, Andrew, Robert J Hodrick, Yuhang Xing, and Xiaoyan Zhang, 2006, The cross-section of volatility and expected returns, Journal of Finance 61, 259-299.

, 2009, High idiosyncratic volatility and low returns: International and further us evidence, Journal of Financial Economics 91, 1-23.

Baker, Steven D., Burton Hollifield, and Emilio Osambela, 2022, Asset prices and portfolios with externalities, Review of Finance 26, 1433-1468.

Baker, Scott R., Nicholas Bloom, and Steven J. Davis, 2016, Measuring economic policy uncertainty, Quarterly Journal of Economics 131, 1593-1636.

Bakkensen, Laura A., and Lint Barrage, 2022, Going underwater? Flood risk belief heterogeneity and coastal home price dynamics, Review of Financial Studies 35, 3666-3709.

Baldauf, Markus, Lorenzo Garlappi, and Constantine Yannelis, 2020, Does climate change affect real estate prices? only if you believe in it, Review of Financial Studies 33, 12561295. 
Barro, Robert J, 2006, Rare disasters and asset markets in the twentieth century, Quarterly Journal of Economics 121, 823-866.

Barrot, J., and J. Sauvagnat, 2016a, Input specificity and the propagation of idiosyncratic shocks in production networks, The Quarterly Journal of Economics 131, 1543-1592.

Barrot, Jean-Noel, and Julien Sauvagnat, 2016b, Input specificity and the propagation of idiosyncratic shocks in production networks, Quarterly Journal of Economics 131, 15431592.

Bernstein, Asaf, Matthew Gustafson, and Ryan Lewis, 2019, Disaster on the horizon: The price effect of sea level rise, Journal of Financial Economics 134, 253-272.

Bertrand, Marianne, Esther Duflo, and Sendhil Mullainathan, 2004, How much should we trust differences-in-differences estimates?, Quarterly Journal of Economics 119, 249-275.

Bloom, Nicholas, 2009, The impact of uncertainty shocks, Econometrica 77, 623-685.

Bollerslev, Tim, 1986, Generalized autoregressive conditional heteroskedasticity, Journal of econometrics 31, 307-327.

Bollerslev, T., G. Tauchen, and H. Zhou, 2009, Expected stock returns and variance risk premia, Review of Financial Studies 22, 4463-4492.

Bolton, Patrick, and Marcin Kacperczyk, 2021, Do investors care about carbon risk?, Journal of Financial Economics 142, 517-549.

Campbell, John, and Robert Shiller, 1988, The dividend-price ratio and expectations of future dividends and discount factors, Review of Financial Studies 1, 195-228.

Carney, Mark, 2015, Breaking the tragedy of the horizon - climate change and financial stability, Speech given at Lloyd's of London (29 September).

Carr, P., and L. Wu, 2009, Variance risk premiums, Review of Financial Studies 22, 13111341.

Chen, Long, Zhi Da, and Xinlei Zhao, 2013, What drives stock price movements, Review of Financial Studies 26, 841-876.

Cheng, Ing-Haw, 2019, The VIX premium, Review of Financial Studies 32, 180-227.

Coval, Joshua D., and Tobias J. Moskowitz, 1999, Home bias at home: Local equity preference in domestic portfolios, Journal of Finance 54, 2045-2073. 
Della Corte, Pasquale, Tarun Ramadorai, and Lucio Sarno, 2016, Volatility risk premia and exchange rate predictability, Journal of Financial Economics 120, 21-40.

Dessaint, Olivier, and Adrien Matray, 2017, Do managers overreact to salient risks? Evidence from hurricane strikes, Journal of Financial Economics 126, 97-121.

Dew-Becker, Ian, Stefano Giglio, and Bryan Kelly, 2021, Hedging macroeconomic and financial uncertainty and volatility, Journal of Financial Economics 142, 23-45.

Dew-Becker, Ian, Stefano Giglio, Anh Le, and Marius Rodriguez, 2017, The price of variance risk, Journal of Financial Economics 123, 225-250.

Duffee, Gregory R, 1995, Stock returns and volatility a firm-level analysis, Journal of Financial Economics 37, 399-420.

Ederington, Louis H, and Jae Ha Lee, 1993, How markets process information: News releases and volatility, The Journal of Finance 48, 1161-1191.

Engle, Robert, Stefano Giglio, Bryan Kelly, Heebum Lee, and Johannes Stroebel, 2020, Hedging climate change news, Review of Financial Studies 33, 1184-1216.

Engle, Robert F, 1982, Autoregressive conditional heteroscedasticity with estimates of the variance of united kingdom inflation, Econometrica: Journal of the econometric society pp. $987-1007$.

Fama, Eugene F, 1965, The behavior of stock-market prices, The journal of Business 38, $34-105$.

Fama, Eugene F., and Kenneth R. French, 2008, Dissecting anomalies, Journal of Finance $63,1653-1678$.

— , 2015, A five-factor asset pricing model, Journal of Financial Economics 116, 1-22.

Fu, Fangjian, 2009, Idiosyncratic risk and the cross-section of expected stock returns, Journal of Financial Economics 91, 24-37.

Giglio, Stefano, Matteo Maggiori, Krishna Rao, Johannes Stroebel, and Andreas Weber, 2021, Climate change and long-run discount rate: Evidence from real estate, Review of Financial Studies Forthcoming.

Goetzmann, William N., and Alok Kumar, 2008, Equity portfolio diversification, Review of Finance 12, 433-463.

Grullon, Gustavo, Evgeny Lyandres, and Alexei Zhdanov, 2012, Real options, volatility, and stock returns, Journal of Finance 67, 1499-1537. 
Hassan, Tarek A, Stephan Hollander, Laurence Van Lent, and Ahmed Tahoun, 2019, Firmlevel political risk: Measurement and effects, The Quarterly Journal of Economics 134, $2135-2202$.

Hong, Harrison, Frank W. Li, and Jiangmin Xu, 2019, Climate risks and market efficiency, Journal of Econometrics 208, 265-281.

Ilhan, Emirhan, Zacharias Sautner, and Grigory Vilkov, 2021, Carbon tail risk, Review of Financial Studies 34, 1540-1571.

Jens, Candace E., 2017, Political uncertainty and investment: Causal evidence from U.S. gubernatorial elections, Journal of Financial Economics 124, 563-579.

Julio, Brandon, and Youngsuk Yook, 2012, Political uncertainty and corporate investment cycles, Journal of Finance 67, 45-83.

Jurado, Kyle, Sydney C. Ludvigson, and Serena Ng, 2015, Measuring uncertainty, American Economic Review 105, 1177-1216.

Kelly, Bryan, Lubos Pastor, and Pietro Veronesi, 2016, The price of political uncertainty: Theory and evidence from the option market, Journal of Finance 71, 2417-2480.

Levy, Haim, 1978, Equilibrium in an imperfect market: A constraint on the number of securities in theportfolio, American Economic Review 68, 643-658.

Lochstoer, Lars A, and Tyler Muir, 2022, Volatility expectations and returns, The Journal of Finance 77, 1055-1096.

Malmendier, Ulrike, and Stefan Nagel, 2016, Learning from inflation experiences, The Quarterly Journal of Economics 131, 53-87.

Mandelbrot, Benoit, 1963, The variation of certain speculative prices, Journal of Business 36, 394-419.

Martin, Ian W.R., and Christian Wagner, 2019, What is the expected return on a stock?, The Journal of Finance 74, 1887-1929.

Menzly, Lior, and Oguzhan Ozbas, 2010, Market segmentation and cross-predictability of returns, The Journal of Finance 65, 1555-1580.

Merton, Robert C., 1987, A simple model of capital market equilibrium with incomplete information, Journal of Finance 42, 483-510.

Murfin, Justin, and Matthew Spiegel, 2020, Is the risk of sea level rise capitalized in residential real estate?, Review of Financial Studies 33, 1217-1255. 
Neumark, David, Brandon Wall, and Junfu Zhang, 2011, Do small businesses create more jobs? New evidence for the united states from the national establishment time series, Review of Economics and Statistics 93, 16-29.

Pankratz, N., and C. Schiller, 2021, Climate change and adaptation in global supply-chain networks, Working Paper.

Pastor, Lubos, Meenakshi Sinha, and Bhaskaran Swaminathan, 2008, Estimating the intertemporal risk-return tradeoff using the implied cost of capital, Journal of Finance 42, 2859-2897.

Pastor, Lubos, and Pietro Veronesi, 2012, Uncertainty about government policy and stock prices, Journal of Finance 67, 1219-1264.

- 2013, Political uncertainty and risk premia, Journal of Financial Economics 110, $520-545$.

Petersen, Mitchell A, 2009, Estimating standard errors in finance panel data sets: Comparing approaches, The Review of financial studies 22, 435-480.

Polkovnichenko, Valery, 2005, Household portfolio diversification: A case for rank-dependent preferences, Review of Financial Studies 18, 1467-1502.

Roth Tran, Brigitte, 2019, Divest, disregard, or double down? Philanthropic endowment investments in objectionable firms, American Economic Review: Insights 2, 241-256.

Sautner, Z., L. van Lent, G. Vilkov, and R. Zhang, 2022a, Firm-level climate change exposure, Journal of Finance, forthcoming.

— , 2022b, Pricing climate change exposure, Management Science, forthcoming.

Strobl, Eric, 2011, The economic growth impact of hurricanes: Evidence from u.s. coastal counties, Review of Economics and Statistics 93, 575-589.

Vuolteenaho, Tuomo, 2002, What drives firm-level stock returns?, Journal of Finance 57, 233-264. 


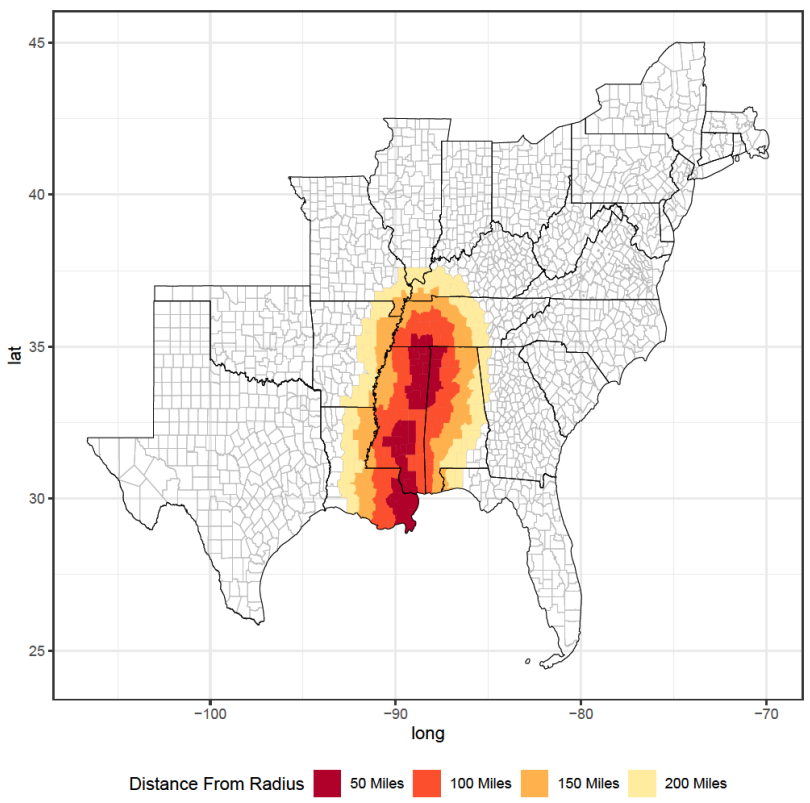

(a) 2005 Katrina

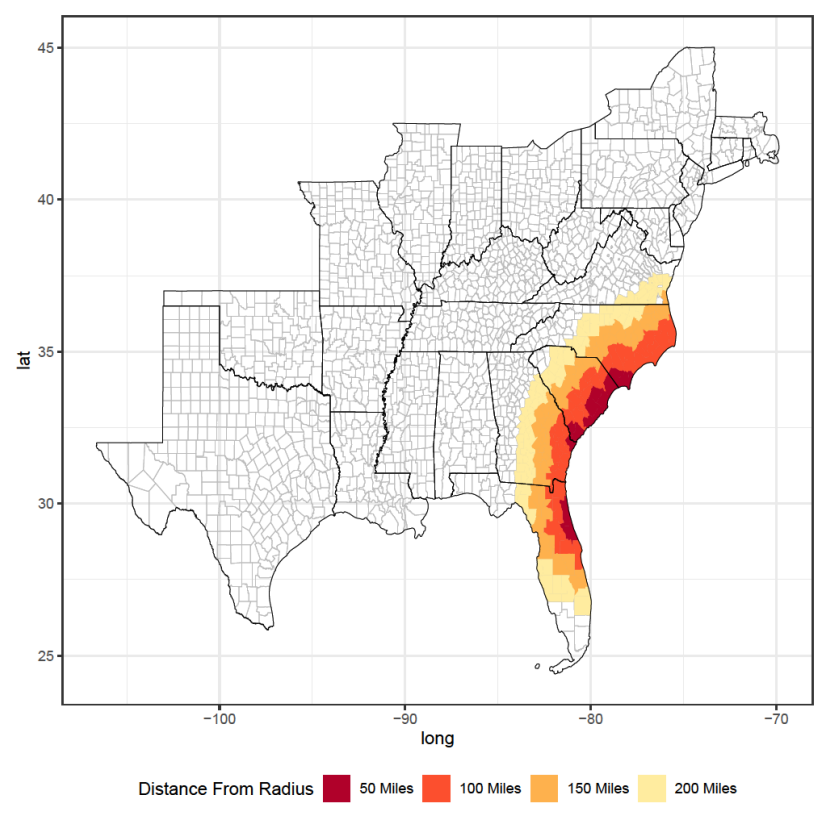

(c) 2016 Matthew

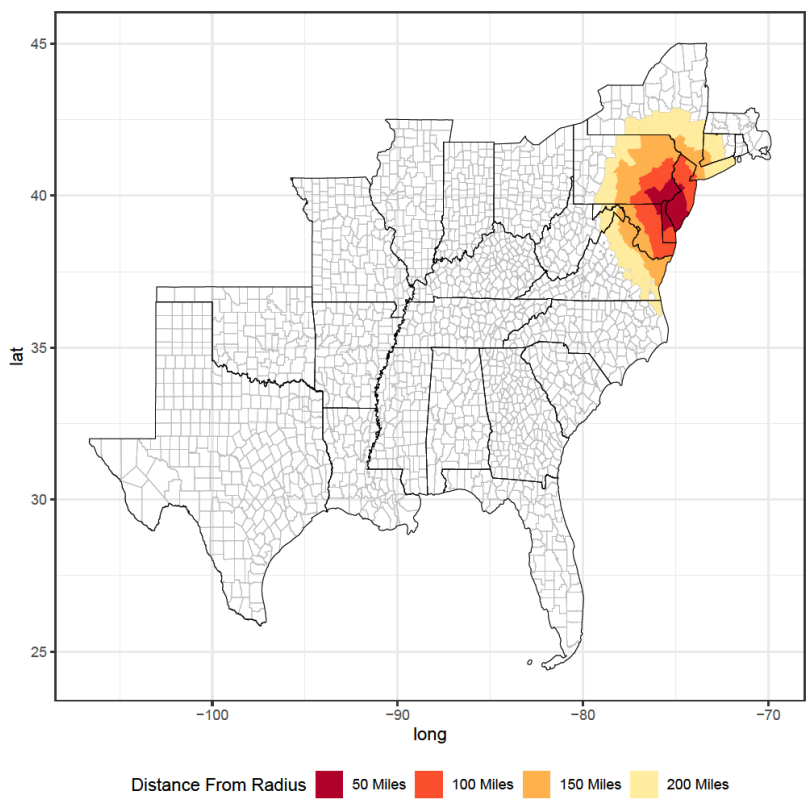

(b) 2012 Sandy

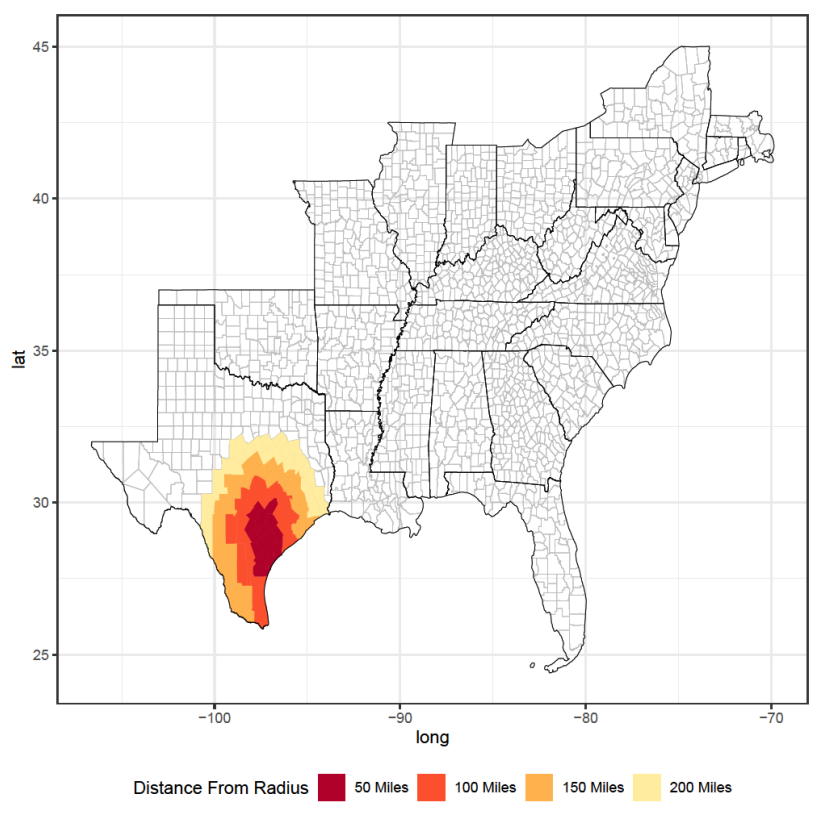

(d) 2017 Harvey

Figure 1: Counties in a hurricane landfall region

This figure highlights the counties that are within 50, 100, 150, and 200 miles of the eye of the hurricane at landfall for four selected hurricanes from our sample of 37 hurricane landfalls. 


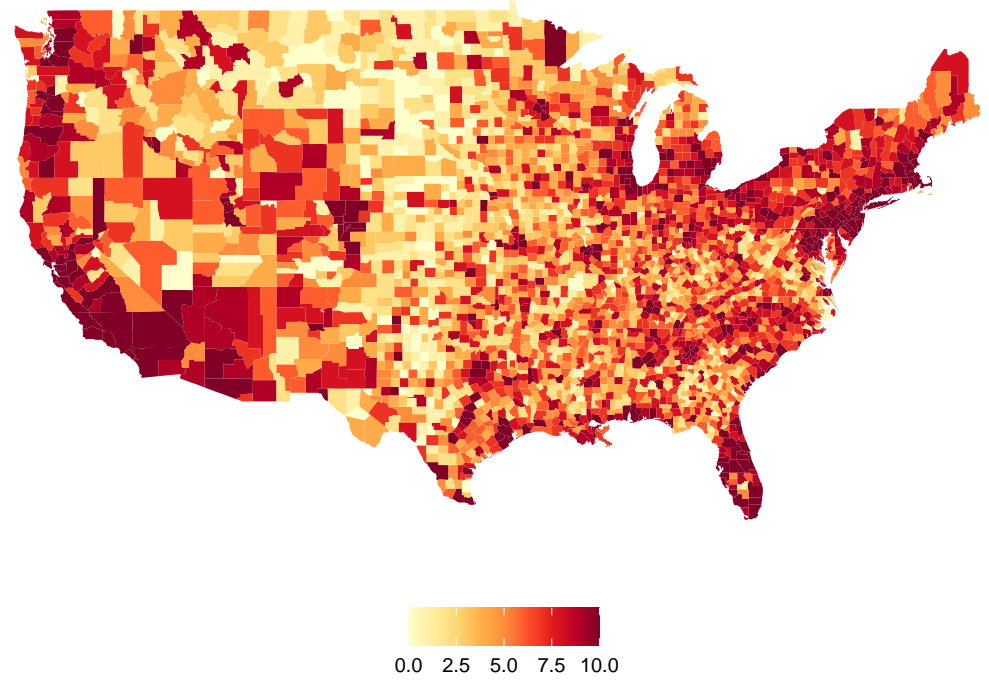

Figure 2: Firm establishments by county

This figure plots counties based on the number of establishments located in that county in 2010. The counties are sorted into deciles based on the number of establishments for the firms in our sample. The darker the shade the greater the number of establishments in a county. Data are from the National Establishment Time Series. 
4 days before landfall

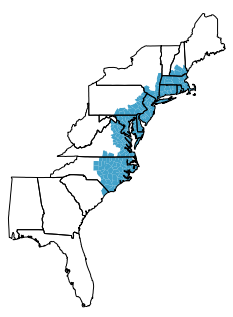

3 days before landfall
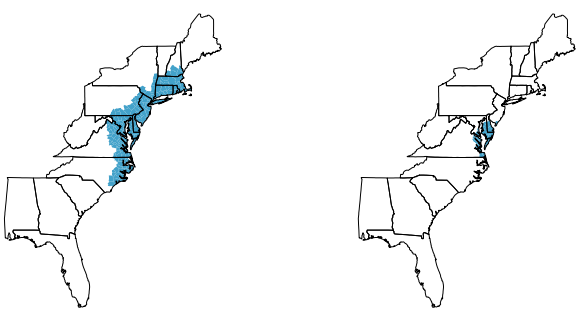

2 days before landfall
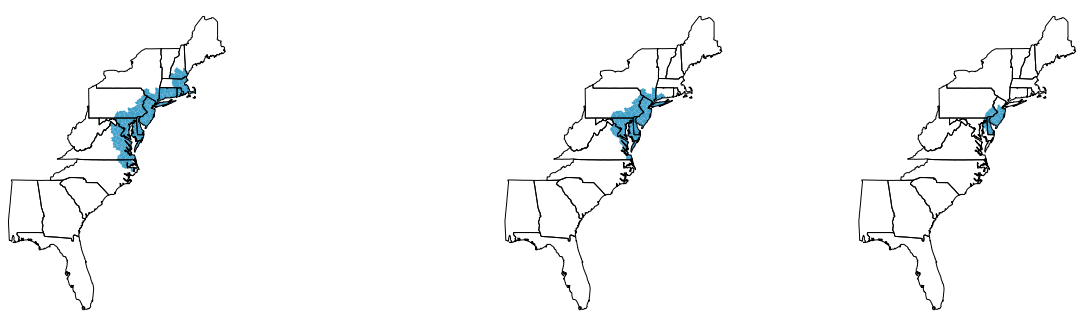

1 day before landfall

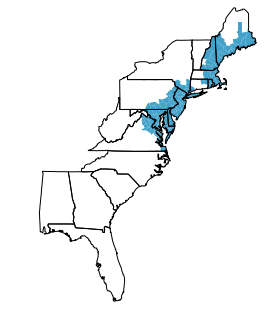

$\geq 1 \%$

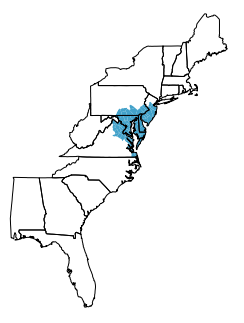

$\geq 10 \%$

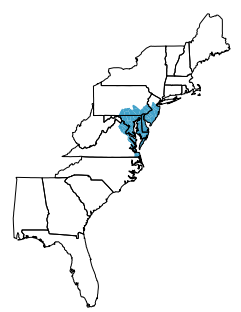

$\geq 20 \%$

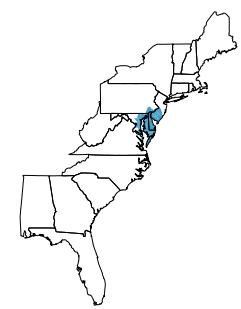

$\geq 50 \%$

Figure 3: Hurricane forecasts by day and wind speed probability threshold

This figure presents an example of the forecast exposure regions after forecast data have been processed. Each map shows the counties included in the forecast path for Hurricane Sandy given the number of days before landfall in each row (from 4 days to 1 day before landfall) and the wind speed probability threshold in each column $(\geq 1 \%, \geq 10 \%, \geq 20 \%$, and $\geq 50 \%)$. 

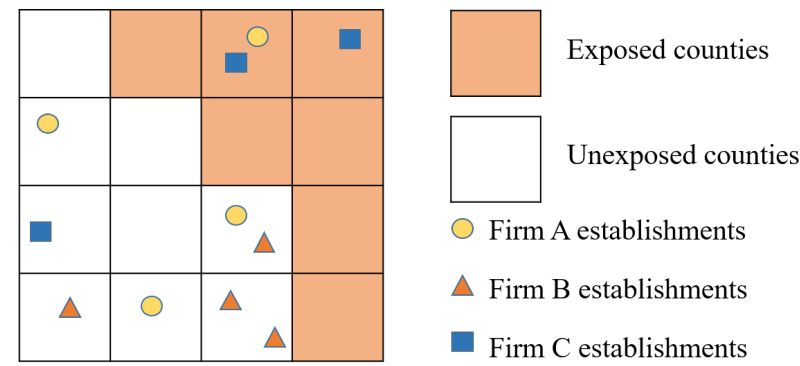

Exposure to hurricane landfall region:

Firm A: $\frac{1}{4}=0.25$ Firm B: $\frac{0}{4}=0.00$ Firm C: $\frac{2}{3}=0.67$

(a) Stylized example of firm exposure

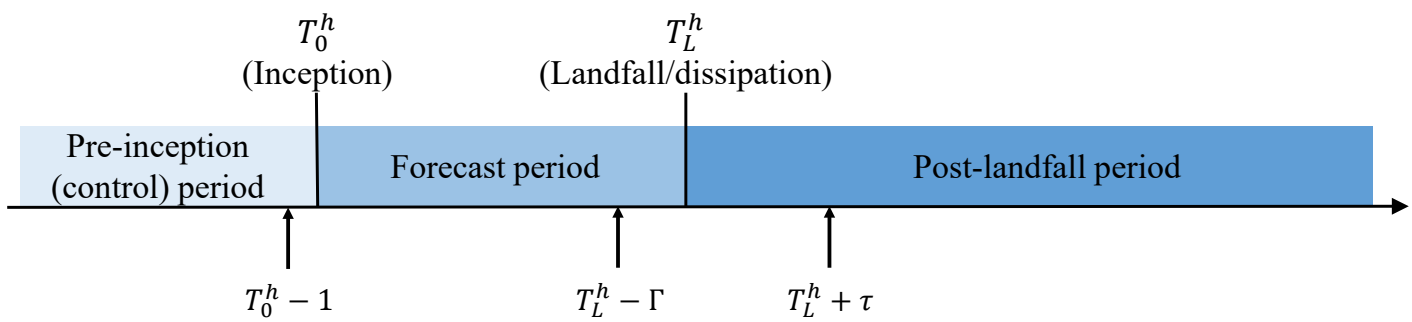

(b) Hurricane timeline

\section{Figure 4: Identification strategy}

Panel A shows a stylized example of firm exposure to a hurricane landfall region based on the share of establishments located in counties in the landfall region. These firm exposures illustrate the variable LandfallRegionExposure in our analysis. Panel B illustrates the timeline of a hurricane. 


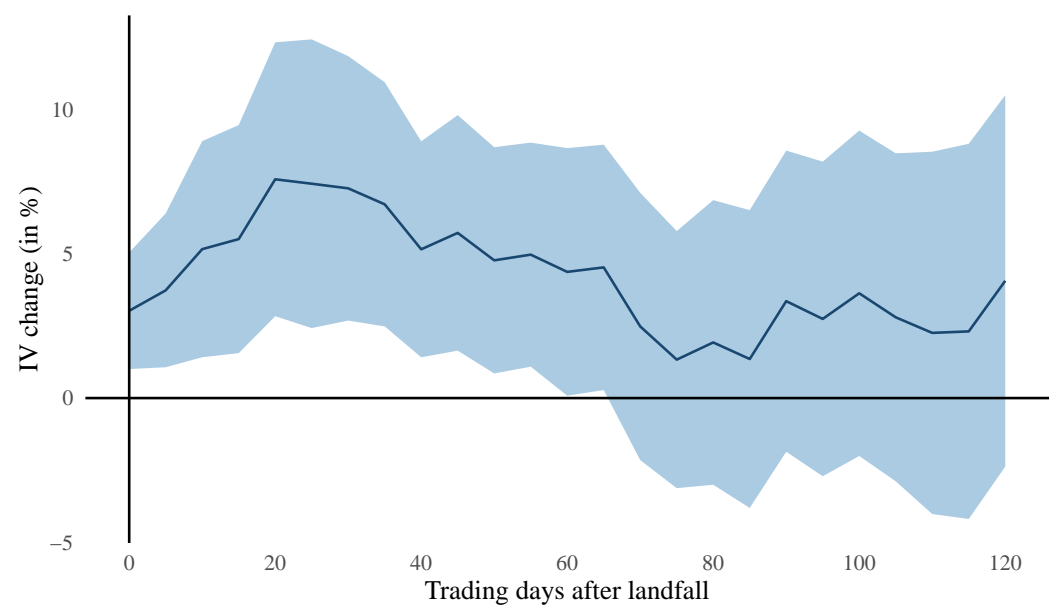

(a) Changes in implied volatilities

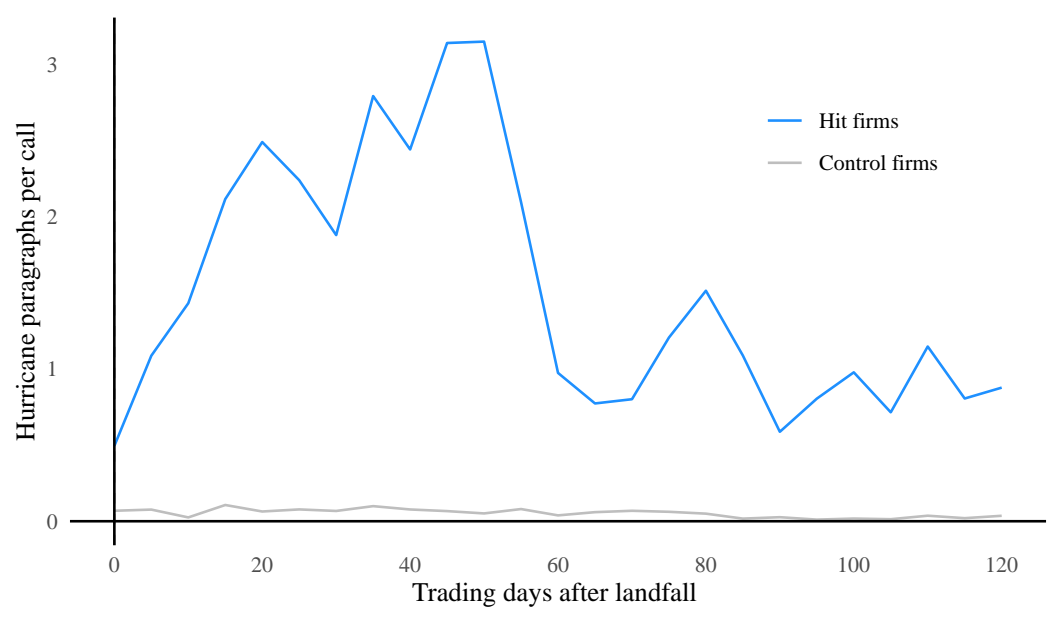

(b) Hurricane mentions in analyst calls

\section{Figure 5: Uncertainty after hurricane landfall}

Panel A plots coefficient estimates from running separate regressions estimating specification (6) when varying the number of trading days after landfall. Changes in implied volatilities from the day before hurricane inception to up to 120 trading days (6 months) post-hurricane landfall are regressed on the share of firm establishments in the landfall region. A coefficient estimate of, for example, 5 means that a firm with all of its establishments in the landfall region is estimated to experience a $5 \%$ increase in implied volatility, relative to control firms with no establishments in the landfall region. The landfall region is based on a 200-mile radius around the hurricane eye. Confidence bands of $95 \%$ are shown. Panel B shows mentions of hurricanes in Refinitiv transcripts of calls between analysts and firm management. Each point reflects the average number of paragraphs per call mentioning hurricanes over the given week. For firms with positive exposure to the landfall region (hit firms), the number of paragraphs are weighted by the firm's landfall exposure. A value of 3 means that a firm with all of its establishments in the landfall region has 3 paragraphs per call discussing hurricanes. 


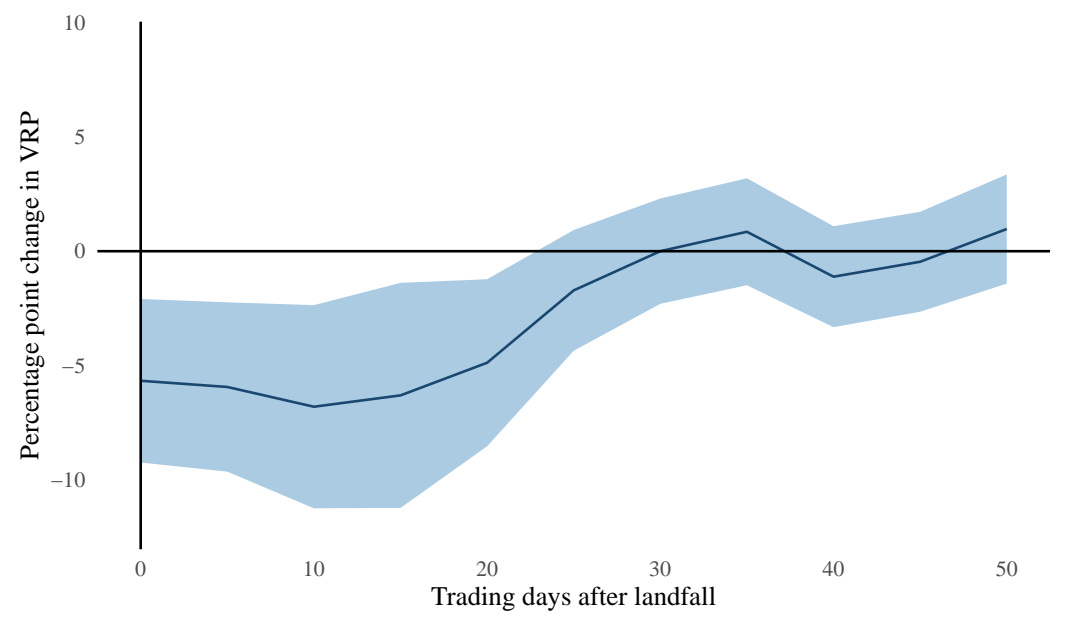

(a) Pre-Sandy

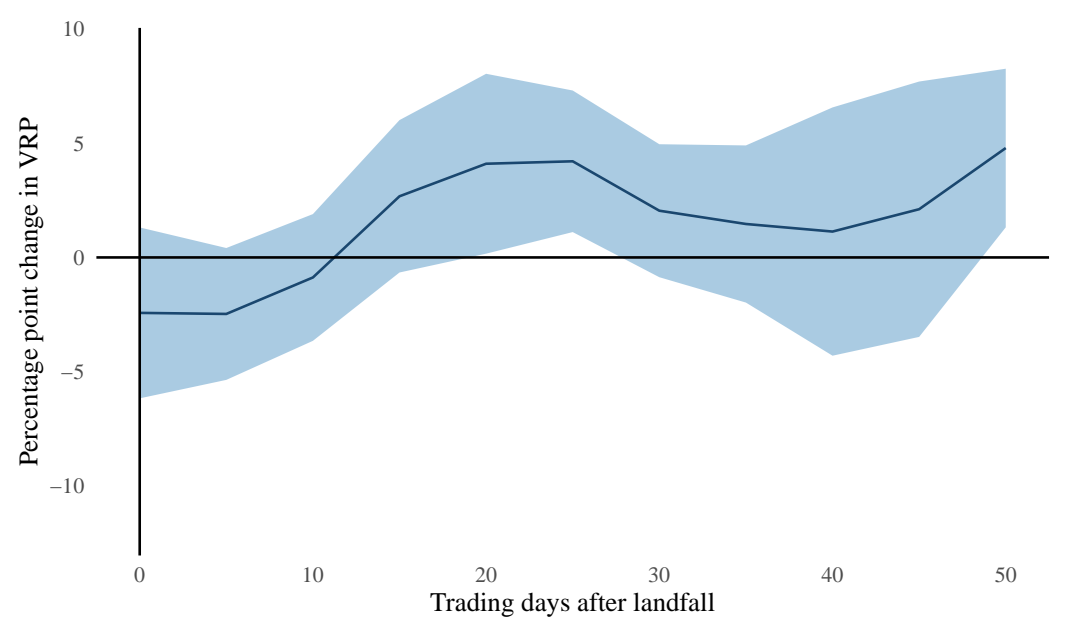

(b) Post-Sandy

\section{Figure 6: Changes in volatility risk premium post hurricane landfall}

This figure plots coefficient estimates when regressing VRP averaged over increments of 5 trading days on the landfall region exposure of a firm, as shown in equation (8). A coefficient estimate of, for example, -5 means that a firm with all of its establishments in the landfall region is estimated to have a 5 percentage points lower VRP than control firms. VRP is the difference between ex ante implied and ex post realized volatility as shown in equation (7). Panel A shows estimates for the subsample of hurricanes from 1996 up to and including Hurricane Sandy in 2012. Panel B shows estimates for the subsample of post-Sandy hurricanes from 2013 to 2019. The landfall region is based on a 200-mile radius around the eye of the hurricane. Confidence bands of $95 \%$ are shown. 


\section{Table 1: Hurricane sample}

Panel A lists the hurricanes in our landfall analyses along with their landfall and inception dates. The damage estimates come from the National Hurricane Center's Tropical Cyclone Reports and have been inflated to 2019 values using the consumer price index from the U.S. Bureau of Labor Statistics. Landfall dates come from the Tropical Cyclone Reports. Panel B lists the storms in the forecast analysis. This sample includes storms that were at some point forecasted to produce hurricane-force winds in U.S. mainland locations with a probability of at least 1 percent. Because the forecasts include storms that ultimately never made landfall in the U.S. (and dissipated out at sea), we indicate storms that made landfall with asterisks $\left(^{*}\right)$.

Panel A: Hurricanes in landfall analyses

\begin{tabular}{|c|c|c|c|c|c|c|c|}
\hline Hurricane & Landfall & Inception & $\begin{array}{l}\text { Damages } \\
2019 \$ \mathrm{mn}\end{array}$ & Hurricane & Landfall & Inception & $\begin{array}{l}\text { Damages } \\
2019 \$ \mathrm{mn}\end{array}$ \\
\hline Bertha & Jul. 12,1996 & Jul. 5, 1996 & 440 & Humberto & Sep. 13, 2007 & Sep. 12,2007 & 62 \\
\hline Fran & Sep. 6, 1996 & Aug. 23, 1996 & 5,214 & Dolly & Jul. 23, 2008 & Jul. 20, 2008 & 1,247 \\
\hline Danny & Jul. 18, 1997 & Jul. 16, 1997 & 159 & Gustav & Sep. 1, 2008 & Aug. 25, 2008 & 5,484 \\
\hline Bonnie & Aug. 27, 1998 & Aug. 19, 1998 & 1,129 & Ike & Sep. 13, 2008 & Sep. 1, 2008 & 35,053 \\
\hline Earl & Sep. 3, 1998 & Aug. 31, 1998 & 124 & Irene & Aug. 27, 2011 & Aug. 21, 2011 & 17,958 \\
\hline Georges & Sep. 28, 1998 & Sep. 15, 1998 & 9,983 & Isaac & Aug. 29, 2012 & Aug. 21, 2012 & 2,617 \\
\hline Bret & Aug. 23, 1999 & Aug. 18, 1999 & 92 & Sandy & Oct. 30,2012 & Oct. 22,2012 & 55,676 \\
\hline Floyd & Sep. 16, 1999 & Sep. 7, 1999 & 10,588 & Arthur & Jul. 4, 2014 & Jul. 1, 2014 & 2 \\
\hline Irene & Oct. 15,1999 & Oct. 13,1999 & 1,228 & Hermine & Sep. 2, 2016 & Aug. 28, 2016 & 586 \\
\hline Lili & Oct. 3,2002 & Sep. 21, 2002 & 1,315 & Matthew & Oct. 8,2016 & Sep. 28, 2016 & 10,652 \\
\hline Claudette & Jul. 15, 2003 & Jul. 8, 2003 & 250 & Harvey & Aug. 26, 2017 & Aug. 17, 2017 & 130,373 \\
\hline Isabel & Sep. 18, 2003 & Sep. 6, 2003 & 7,461 & Irma & Sep. 10, 2017 & Aug. 30, 2017 & 52,149 \\
\hline Charley & Aug. 13, 2004 & Aug. 9, 2004 & 20,454 & Nate & Oct. 8, 2017 & Oct. 4,2017 & 235 \\
\hline Frances & Sep. 5, 2004 & Aug. 25, 2004 & 12,867 & Florence & Sep. 14,2018 & Aug. 31, 2018 & 24,435 \\
\hline Ivan & Sep. 16, 2004 & Sep. 2, 2004 & 25,471 & Michael & Oct. 10,2018 & Oct. 7,2018 & 25,453 \\
\hline Jeanne & Sep. 26, 2004 & Sep. 13, 2004 & 10,367 & Barry & Jul. 13, 2019 & Jul. 11, 2019 & 600 \\
\hline Dennis & Jul. 10, 2005 & Jul. 4, 2005 & 3,332 & Dorian & Sep. 6, 2019 & Aug. 24, 2019 & 1,600 \\
\hline Katrina & Aug. 29, 2005 & Aug. 23, 2005 & 141,377 & & & & \\
\hline Rita & Sep. 24, 2005 & Sep. 18, 2005 & 15,757 & & & & \\
\hline Wilma & Oct. 24,2005 & Oct. 15,2005 & 27,499 & & & & \\
\hline
\end{tabular}

Panel B: Storms in forecast analyses

\begin{tabular}{|c|c|c|c|c|c|c|c|c|c|c|c|c|}
\hline 2007 & 2008 & 2009 & 2010 & 2011 & 2012 & 2013 & 2014 & 2015 & 2016 & 2017 & 2018 & 2019 \\
\hline Dean & Dolly* & Ana & Alex & Don & Debby & Andrea & Arthur* & Ana & Colin & Cindy & Alberto & Barry* \\
\hline \multirow[t]{7}{*}{ Noel } & Edouard & Bill & Bonnie & Emily & Ernesto & Karen & & Bill & Herm.* & Harvey* & Chris & Dorian* \\
\hline & Fay & Danny & Earl & Irene* & Isaac* & & & Erika & Matt.* & Irma* & Florence* & \\
\hline & Gustav* & Ida & Paula & Katia & Leslie & & & Joaquin & & Jose & Gordon & \\
\hline & Hanna & & Richard & Nate & Sandy* & & & & & Maria & Michael* & \\
\hline & Ike* & & & & & & & & & Nate* & & \\
\hline & Kyle & & & & & & & & & & & \\
\hline & Paloma & & & & & & & & & & & \\
\hline
\end{tabular}




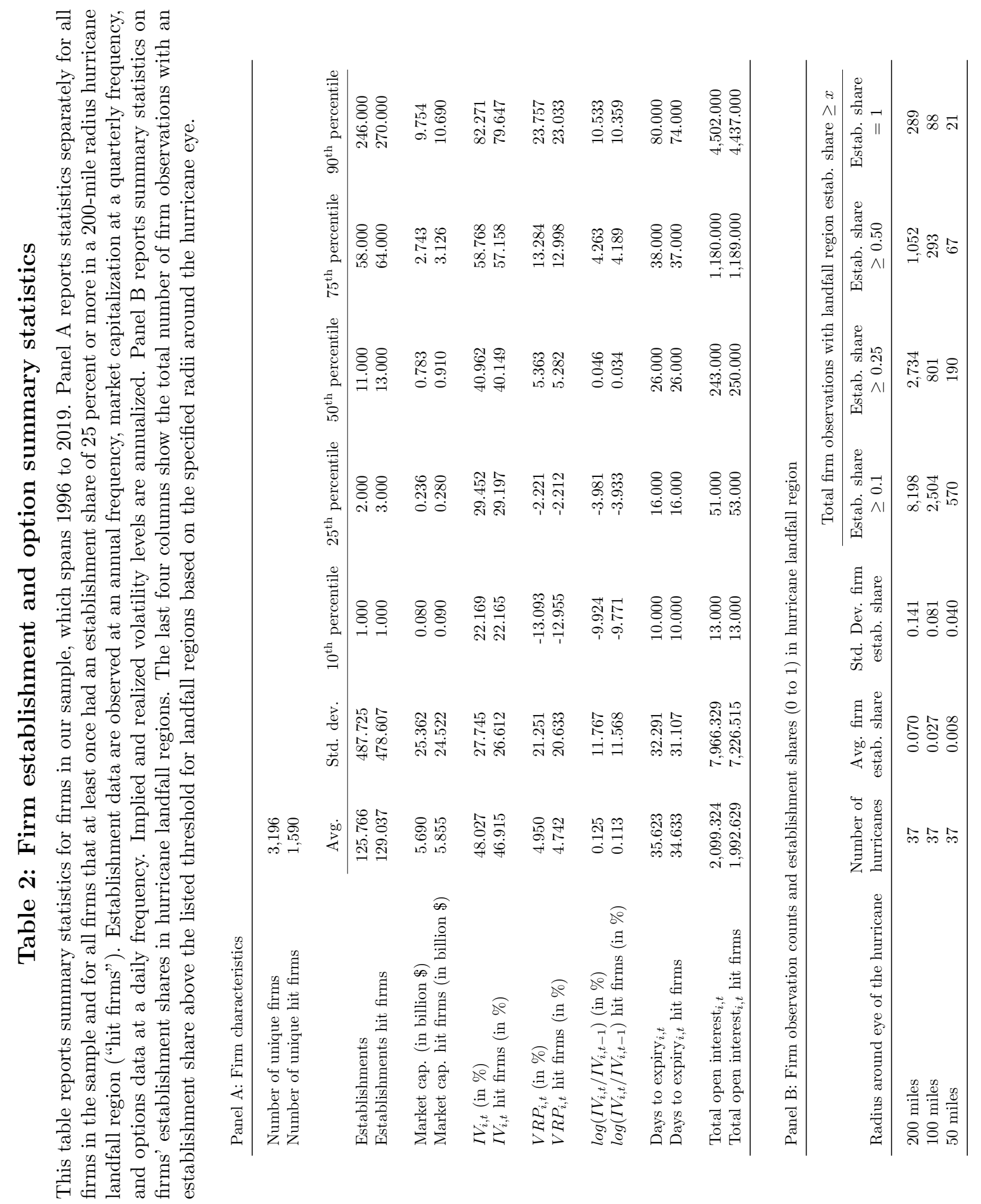




\section{Table 3: Hurricane effects on implied volatility}

This table reports coefficients and test statistics from estimating the panel model in equation (6). The dependent variable is the change (in \%) in implied volatility of firm $i$ from the trading day before hurricane inception $\left(T_{0}^{h}-1\right)$ to 1 week (5 trading days) and 1 month (20 trading days) after landfall $\left(T_{L}^{h}+5\right.$ and $T_{L}^{h}+20$, respectively). The independent variable is the share (from 0 to 1 ) of a firm's establishments that are within a radius of 200 miles (Panel A), 100 miles (Panel B), or 50 miles (Panel C) around the hurricane eye at landfall. The data span 1996 to 2019. T-statistics are shown in parentheses. The standard errors are clustered by county based on a firm's largest establishment share. Industry, time, and industry interacted with time fixed effects are included as specified. The time fixed effect can be interpreted as a hurricane fixed effect because each hurricane enters the regression as one separate time period, as shown in equation (6). The significance of each coefficient estimate is indicated by * for $p<0.10,{ }^{* *}$ for $p<0.05$, and ${ }^{* * *}$ for $p<$ 0.01 .

Panel A: 200-mile radius landfall region

\begin{tabular}{|c|c|c|c|c|c|c|}
\hline \multicolumn{4}{|c|}{ Dependent variable: Change in IV (in \%), $\log \left(I V_{i, T_{L}^{h}+\tau} / I V_{i, T_{0}^{h}-1}\right)$} & & & \\
\hline \multirow[b]{2}{*}{ LandfallRegionExposure $e_{i, R, T_{L}^{h}}$} & \multicolumn{3}{|c|}{1 week post landfall } & \multicolumn{3}{|c|}{1 month post landfall } \\
\hline & $\begin{array}{r}3.622^{* * *} \\
(2.640)\end{array}$ & $\begin{array}{r}3.732^{* * *} \\
(2.745)\end{array}$ & $\begin{array}{l}2.688^{* *} \\
(2.120)\end{array}$ & $\begin{array}{r}7.576^{* * *} \\
(3.106)\end{array}$ & $\begin{array}{r}7.581^{* * *} \\
(3.131)\end{array}$ & $\begin{array}{r}6.079^{* * *} \\
(2.790)\end{array}$ \\
\hline Adjusted $\mathrm{R}^{2}(\%)$ & 12.398 & 12.403 & 12.884 & 24.521 & 24.549 & 25.036 \\
\hline Observations & 38,881 & 38,881 & 38,881 & 38,910 & 38,910 & 38,910 \\
\hline Hurricanes & 37 & 37 & 37 & 37 & 37 & 37 \\
\hline Industry FE & No & Yes & No & No & Yes & No \\
\hline Time (Hurricane) FE & Yes & Yes & No & Yes & Yes & No \\
\hline Industry $\times$ Time (Hurricane) FE & No & No & Yes & No & No & Yes \\
\hline
\end{tabular}

Panel B: 100-mile radius landfall region

\begin{tabular}{lrrrrrr}
\hline LandfallRegion Exposure $i, R, T_{L}^{h}$ & $\begin{array}{r}6.768^{* * *} \\
(3.409)\end{array}$ & $\begin{array}{r}6.887^{* * *} \\
(3.470)\end{array}$ & $\begin{array}{r}5.534^{* * *} \\
(2.902)\end{array}$ & $\begin{array}{r}9.340^{* * *} \\
(2.768)\end{array}$ & $\begin{array}{r}9.266^{* * *} \\
(2.749)\end{array}$ & $\begin{array}{r}6.943^{* *} \\
(2.386)\end{array}$ \\
\hline Adjusted R ${ }^{2}(\%)$ & 12.630 & 12.631 & 13.115 & 25.420 & 25.431 & 25.987 \\
Observations & 33,306 & 33,306 & 33,306 & 33,326 & 33,326 & 33,326 \\
Hurricanes & 37 & 37 & 37 & 37 & 37 & 37 \\
\hline Industry FE & No & Yes & No & No & Yes & No \\
Time (Hurricane) FE & Yes & Yes & No & Yes & Yes & No \\
Industry $\times$ Time (Hurricane) FE & No & No & Yes & No & No & Yes \\
\hline
\end{tabular}

Panel C: 50-mile radius landfall region

\begin{tabular}{lrrrrrr}
\hline LandfallRegionExposure $i, R, T_{L}^{h}$ & $\begin{array}{r}11.434^{* *} \\
(2.411)\end{array}$ & $\begin{array}{r}11.495^{* *} \\
(2.427)\end{array}$ & $\begin{array}{r}7.966^{*} \\
(1.889)\end{array}$ & $\begin{array}{r}17.843^{*} \\
(1.915)\end{array}$ & $\begin{array}{r}17.630^{*} \\
(1.872)\end{array}$ & $\begin{array}{r}10.428 \\
(1.366)\end{array}$ \\
\hline Adjusted R ${ }^{2}(\%)$ & 12.184 & 12.189 & 12.720 & 25.131 & 25.145 & 25.747 \\
Observations & 28,037 & 28,037 & 28,037 & 28,045 & 28,045 & 28,045 \\
Hurricanes & 37 & 37 & 37 & 37 & 37 & 37 \\
\hline Industry FE & No & Yes & No & No & Yes & No \\
Time (Hurricane) FE & Yes & Yes & No & Yes & Yes & No \\
Industry $\times$ Time (Hurricane) FE & No & No & Yes & No & No & Yes \\
\hline
\end{tabular}




\section{Table 4: Hurricane effects on volatility risk premium}

This table reports coefficients and test statistics from estimating the panel model in equation (8). The dependent variable is the VRP (in \%) averaged over 1 week, 1 month, and 2 months (5, 20, and 40 trading days, respectively) after landfall. The VRP is computed as the difference between the ex ante implied and ex post realized volatility, as specified in equation (7). The independent variable is the share (from 0 to 1 ) of a firm's establishments that are within a radius of 200 miles (Panel A) and 50 miles (Panel B) around the hurricane eye at landfall. The data span 1996 to 2019. T-statistics are shown in parentheses. The standard errors are clustered by county based on a firm's largest establishment share. Industry, time, and industry interacted with time fixed effects are included as specified. The time fixed effect can be interpreted as a hurricane fixed effect because each hurricane enters the regression as one separate time period, as per equation (8). The significance of each coefficient estimate is indicated by $*$ for $p<0.10$, ** for $p<0.05$, and $* * *$ for $p<0.01$.

Panel A: 200-mile radius landfall region

\begin{tabular}{|c|c|c|c|c|c|c|c|c|c|}
\hline \multicolumn{10}{|c|}{ Dependent variable: VRP (in \%) avg. over $\tau$ trading days post landfall, $\overline{V R P}_{i, T_{L}^{h}+\tau}$} \\
\hline \multirow[b]{2}{*}{ LandfallRegionExposure $_{i, R, h}$} & \multicolumn{3}{|c|}{1 week post landfall } & \multicolumn{3}{|c|}{1 month post landfall } & \multicolumn{3}{|c|}{2 months post landfall } \\
\hline & $\begin{array}{r}-6.035^{* * *} \\
(-4.414)\end{array}$ & $\begin{array}{r}-4.655^{* * *} \\
(-3.607)\end{array}$ & $\begin{array}{r}-2.918^{* * *} \\
(-2.798)\end{array}$ & $\begin{array}{r}-5.315^{* * *} \\
(-3.043)\end{array}$ & $\begin{array}{r}-3.727^{* * *} \\
(-2.606)\end{array}$ & $\begin{array}{c}-1.753^{*} \\
(-1.937)\end{array}$ & $\begin{array}{r}-3.566^{* * *} \\
(-2.752)\end{array}$ & $\begin{array}{r}-1.467 \\
(-1.492)\end{array}$ & $\begin{array}{r}0.165 \\
(0.241)\end{array}$ \\
\hline Adjusted $\mathrm{R}^{2}(\%)$ & 17.206 & 26.914 & 28.221 & 22.454 & 34.212 & 35.491 & 22.653 & 38.599 & 40.001 \\
\hline Observations & 36,539 & 36,539 & 36,539 & 36,675 & 36,675 & 36,675 & 36,674 & 36,674 & 36,674 \\
\hline Hurricanes & 37 & 37 & 37 & 37 & 37 & 37 & 37 & 37 & 37 \\
\hline Firm FE & No & Yes & Yes & No & Yes & Yes & No & Yes & Yes \\
\hline Time (Hurricane) FE & Yes & Yes & No & Yes & Yes & No & Yes & Yes & No \\
\hline Industry X Time (Hurricane) FE & No & No & Yes & No & No & Yes & No & No & Yes \\
\hline
\end{tabular}

Panel B: 50-mile radius landfall region

\begin{tabular}{|c|c|c|c|c|c|c|c|c|c|}
\hline Landf allRegionExposure $e_{i, R, h}$ & $\begin{array}{r}-21.463^{* * *} \\
(-3.286)\end{array}$ & $\begin{array}{r}-16.123^{* *} \\
(-2.139)\end{array}$ & $\begin{array}{c}-8.799^{* *} \\
(-2.050)\end{array}$ & $\begin{array}{r}-21.232^{* * *} \\
(-3.012)\end{array}$ & $\begin{array}{r}-15.523^{*} \\
(-1.871)\end{array}$ & $\begin{array}{l}-7.828^{*} \\
(-1.695)\end{array}$ & $\begin{array}{r}-14.679^{* * *} \\
(-3.030)\end{array}$ & $\begin{array}{r}-8.895 \\
(-1.612)\end{array}$ & $\begin{array}{r}-2.268 \\
(-0.761)\end{array}$ \\
\hline Adjusted $\mathrm{R}^{2}(\%)$ & 16.854 & 26.410 & 27.766 & 20.959 & 32.925 & 34.080 & 20.494 & 37.368 & 38.648 \\
\hline Observations & 26,090 & 26,090 & 26,090 & 26,185 & 26,185 & 26,185 & 26,166 & 26,166 & 26,166 \\
\hline Hurricanes & 37 & 37 & 37 & 37 & 37 & 37 & 37 & 37 & 37 \\
\hline Firm FE & No & Yes & Yes & No & Yes & Yes & No & Yes & Yes \\
\hline Time (Hurricane) FE & Yes & Yes & No & Yes & Yes & No & Yes & Yes & No \\
\hline Industry X Time (Hurricane) FE & No & No & Yes & No & No & Yes & No & No & Yes \\
\hline
\end{tabular}




\section{Table 5: Hurricane effects on volatility risk premium post Sandy}

This table reports the coefficients and test statistics when estimating the panel model in equation (8) with a post-Sandy (post-2012) interaction term added. The dependent variable is the VRP (in \%) averaged over 1 week, 1 month, and 2 months (5, 20, and 40 trading days, respectively) after landfall. The VRP is computed as the difference between the ex ante implied and ex post realized volatility, as specified in equation (7). The independent variable is the share (from 0 to 1 ) of a firm's establishments that are within a radius of 200 miles around the hurricane eye at landfall. In addition, the landfall region exposure variable is interacted with a dummy variable that equals 1 for all hurricanes post Sandy (after 2012). The data span 1996 to 2019. T-statistics are shown in parentheses. The standard errors are clustered by county based on a firm's largest establishment share. Firm, time, and time interacted with industry fixed effects are included as specified. The time fixed effect can be interpreted as a hurricane fixed effect because each hurricane enters the regression as one separate time period, as per equation (8). The significance of each coefficient estimate is indicated by $*$ for $p<0.10,{ }^{* *}$ for $p<0.05$, and $* * *$ for $p<0.01$.

\begin{tabular}{|c|c|c|c|c|c|c|c|c|c|}
\hline \multirow[b]{2}{*}{ LandfallRegionExposure $_{i, R, h}$} & \multicolumn{3}{|c|}{1 week post landfall } & \multicolumn{3}{|c|}{1 month post landfall } & \multicolumn{3}{|c|}{2 months post landfall } \\
\hline & $\begin{array}{r}-7.579^{* * *} \\
(-3.701)\end{array}$ & $\begin{array}{r}-5.807^{* * *} \\
(-3.302)\end{array}$ & $\begin{array}{r}-3.317^{* *} \\
(-2.543)\end{array}$ & $\begin{array}{r}-7.843^{* * *} \\
(-3.271)\end{array}$ & $\begin{array}{r}-5.835^{* * *} \\
(-2.917)\end{array}$ & $\begin{array}{r}-3.167^{* * *} \\
(-2.661)\end{array}$ & $\begin{array}{r}-4.838^{* * *} \\
(-2.914)\end{array}$ & $\begin{array}{l}-2.788^{* *} \\
(-2.289)\end{array}$ & $\begin{array}{r}-0.755 \\
(-0.884)\end{array}$ \\
\hline $\begin{array}{l}\text { LandfallRegionExposure }_{i, R, h} \\
\quad \times \text { PostSandy }_{h}\end{array}$ & $\begin{array}{l}4.620^{*} \\
(1.651)\end{array}$ & $\begin{array}{r}3.677^{*} \\
(1.761)\end{array}$ & $\begin{array}{r}1.237 \\
(0.676)\end{array}$ & $\begin{array}{r}7.572^{* * *} \\
(2.739)\end{array}$ & $\begin{array}{r}6.718^{* * *} \\
(3.132)\end{array}$ & $\begin{array}{r}4.372^{* * *} \\
(2.732)\end{array}$ & $\begin{array}{r}3.891^{*} \\
(1.932)\end{array}$ & $\begin{array}{r}4.299^{* * *} \\
(3.532)\end{array}$ & $\begin{array}{l}2.905^{* *} \\
(2.471)\end{array}$ \\
\hline Adjusted $\mathrm{R}^{2}(\%)$ & 17.221 & 26.921 & 28.220 & 22.506 & 34.247 & 35.504 & 22.672 & 38.619 & 40.009 \\
\hline Observations & 36,539 & 36,539 & 36,539 & 36,675 & 36,675 & 36,675 & 36,674 & 36,674 & 36,674 \\
\hline Hurricanes & 37 & 37 & 37 & 37 & 37 & 37 & 37 & 37 & 37 \\
\hline Firm FE & No & Yes & Yes & No & Yes & Yes & No & Yes & Yes \\
\hline Time (Hurricane) FE & Yes & Yes & No & Yes & Yes & No & Yes & Yes & No \\
\hline Industry X Time (Hurricane) FE & No & No & Yes & No & No & Yes & No & No & Yes \\
\hline
\end{tabular}




\section{Table 6: Real channels of hurricane impacts}

This table reports coefficients and test statistics of panel regressions using transcript data of calls between analysts and firm management to analyze through which real channels a firm is affected after exposure to hurricane landfall. In column (1), the dependent variable is the count of call paragraphs mentioning hurricanes after landfall. In columns (2) to (6), the dependent variables are the number of paragraphs mentioning hurricanes together with at least one term associated with the designated channel: business interruption, physical damages, insurance, supply, and demand, respectively. Internet Appendix Table C.1 presents the dictionary of discussion terms for each channel. The independent variable is the share (from 0 to 1) of a firm's establishments that are within a radius of 200 miles around the hurricane eye at landfall. The data span 2002 to 2019. T-statistics are shown in parentheses. The standard errors are clustered by county based on a firm's largest establishment share. Industry and time fixed effects are included. The time fixed effect can be interpreted as a hurricane fixed effect because each hurricane enters the regression as one separate time period. The significance of each coefficient estimate is indicated by $*$ for $p<0.10$, ** for $p<$ 0.05 , and $* * *$ for $p<0.01$.

\begin{tabular}{lcccccc}
\hline & & \multicolumn{5}{c}{ Mention of hurricane and channel } \\
\cline { 3 - 7 } & $\begin{array}{c}\text { Hurricane } \\
\text { mentions }\end{array}$ & $\begin{array}{c}\text { Business } \\
\text { interruption }\end{array}$ & $\begin{array}{c}\text { Physical } \\
\text { damages }\end{array}$ & Insurance & Supply & Demand \\
\hline LandfallRegionExposure $_{i, R, T_{L}^{h}}$ & $5.082^{* * *}$ & $1.258^{* * *}$ & $1.610^{* * *}$ & $0.503^{* *}$ & 0.180 & $0.610^{* *}$ \\
& $(6.755)$ & $(4.365)$ & $(5.295)$ & $(2.132)$ & $(1.214)$ & $(2.305)$ \\
\hline Industry FE & Yes & Yes & Yes & Yes & Yes & Yes \\
Time (Hurricane) FE & Yes & Yes & Yes & Yes & Yes & Yes \\
\hline Adjusted R R $^{2}$ (\%) & 16.240 & 11.141 & 11.947 & 5.890 & 7.232 & 3.818 \\
Observations & 11,487 & 3,278 & 3,278 & 3,278 & 3,278 & 3,278 \\
Obs. Landfall Exposure $>0$ & 8,849 & 3,035 & 3,035 & 3,035 & 3,035 & 3,035 \\
Obs. Landfall Exposure $\geq 0.25$ & 900 & 348 & 348 & 348 & 348 & 348 \\
Hurricanes & 24 & 24 & 24 & 24 & 24 & 24 \\
\hline
\end{tabular}




\section{Table 7: Real channels and volatility risk premium}

This table reports the coefficients and test statistics of panel regressions estimating how volatility risk premia respond to hurricane landfall exposure under different real channels of impact. The dependent variable is the VRP (in \%) averaged over the first week (5 trading days) after landfall. The VRP is computed as the difference between the ex ante implied and ex post realized volatility, as specified in equation (7). The independent variable is the share (from 0 to 1 ) of a firm's establishments that are in the 200-mile radius landfall region of a hurricane interacted with the number of paragraphs mentioning both the specified channel and hurricanes in transcripts of post-landfall calls between analysts and firm management. The columns show results, respectively, for the business interruption, physical damages, insurance, supply, and demand channels. Internet Appendix Table C.1 presents the dictionary of discussion terms identifying each channel. The data span 2002 to 2019. T-statistics are shown in parentheses. The standard errors are clustered by county based on a firm's largest exposure. Controls include landfall exposure on its own and landfall exposure interacted with an indicator for hurricane mention. Firm and time fixed effects are included. The time fixed effect can be interpreted as a hurricane fixed effect because each hurricane enters the regression as one separate time period. The significance of each coefficient estimate is indicated by ${ }^{*}$ for $p<0.10,{ }^{* *}$ for $p<0.05$, and ${ }^{* * *}$ for $p<0.01$.

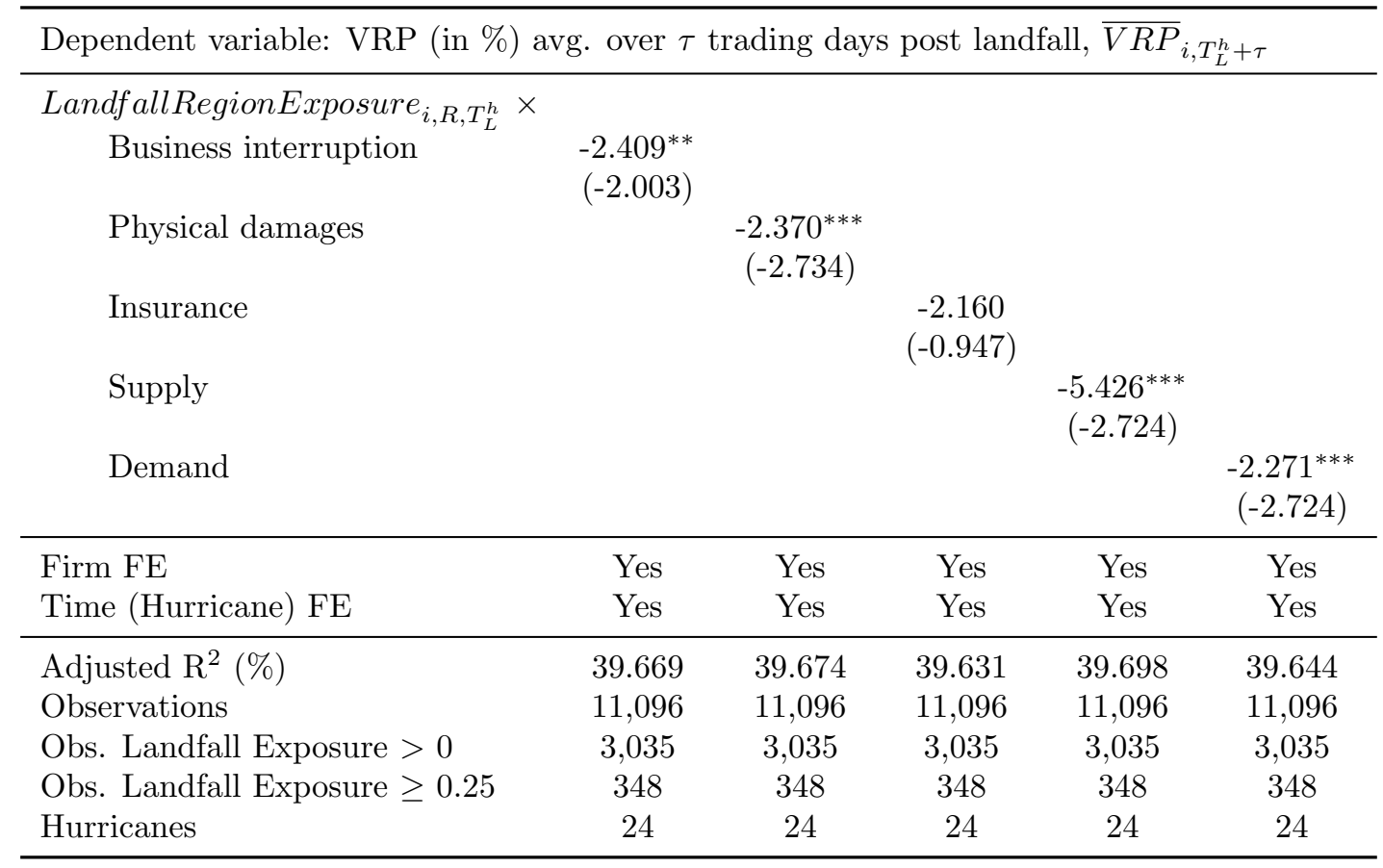




\section{Table 8: Discount rates and cash flows}

This table reports the decomposition of quarterly and semi-annual return variation, $\operatorname{Var}(\operatorname{Ret} x)$, into shares attributable to discount rate and cash flows news for hit and control firms. The differences between hit and control firms' shares of discount rate and cash flow news are also shown. As discussed in Section 4.4.1, the discount rate and cash flow news shares are estimated with a pooled panel regression that regresses discount rate and cash flow return components given in equations (11) and (10), respectively, on capital gain returns. Hit firms have at least $25 \%$ of their establishments in the landfall region of a hurricane in a given quarter or semi-annual period. The landfall region is defined based on a 200-mile radius (Panel A) and a 50-mile radius (Panel B) from the hurricane eye. The data span 1996 to 2019. For each estimate, 95\% confidence bands are shown. The standard errors are clustered by firm and time.

Panel A: 200-mile radius landfall region

\begin{tabular}{|c|c|c|c|c|c|c|}
\hline & \multicolumn{3}{|c|}{ Quarterly horizon } & \multicolumn{3}{|c|}{ Semi-annual horizon } \\
\hline & Hit & Control & Hit-Control & Hit & Control & Hit-Control \\
\hline \multicolumn{7}{|l|}{ Decomposition } \\
\hline Cash Flow & 0.116 & 0.344 & -0.228 & 0.358 & 0.527 & -0.169 \\
\hline $2.5 \%$ & -0.143 & 0.263 & -0.499 & 0.231 & 0.387 & -0.358 \\
\hline $97.5 \%$ & 0.375 & 0.425 & 0.043 & 0.485 & 0.667 & 0.020 \\
\hline Discount Rate & 0.884 & 0.656 & 0.228 & 0.642 & 0.473 & 0.169 \\
\hline $2.5 \%$ & 0.625 & 0.575 & -0.043 & 0.515 & 0.333 & -0.020 \\
\hline $97.5 \%$ & 1.143 & 0.737 & 0.499 & 0.769 & 0.613 & 0.358 \\
\hline Observations & 2,285 & 18,087 & & 2,040 & 12,304 & \\
\hline $\operatorname{Var}(\operatorname{Ret} x)($ in $\%)$ & 4.924 & 4.477 & & 19.817 & 8.941 & \\
\hline
\end{tabular}

Panel B: 50-mile radius landfall region

\begin{tabular}{|c|c|c|c|c|c|c|}
\hline & \multicolumn{3}{|c|}{ Quarterly horizon } & \multicolumn{3}{|c|}{ Semi-annual horizon } \\
\hline & Hit & Control & Hit-Control & Hit & Control & Hit-Control \\
\hline \multicolumn{7}{|l|}{ Decomposition } \\
\hline Cash Flow & 0.064 & 0.302 & -0.238 & 0.485 & 0.472 & 0.013 \\
\hline $2.5 \%$ & -0.291 & 0.235 & -0.600 & 0.452 & 0.292 & -0.170 \\
\hline $97.5 \%$ & 0.419 & 0.370 & 0.123 & 0.518 & 0.653 & 0.197 \\
\hline Discount Rate & 0.936 & 0.698 & 0.238 & 0.515 & 0.528 & -0.013 \\
\hline $2.5 \%$ & 0.581 & 0.630 & -0.123 & 0.482 & 0.347 & -0.197 \\
\hline $97.5 \%$ & 1.291 & 0.765 & 0.600 & 0.548 & 0.708 & 0.170 \\
\hline Observations & 174 & 15,658 & & 154 & 11,532 & \\
\hline $\operatorname{Var}(\operatorname{Ret} x)($ in $\%)$ & 8.335 & 5.107 & & 27.019 & 10.948 & \\
\hline
\end{tabular}




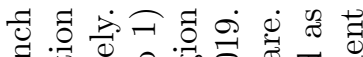
记 屯.

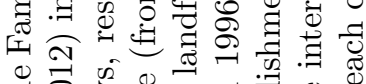

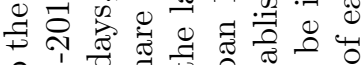

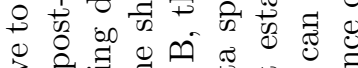
.

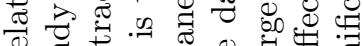

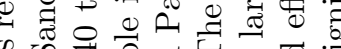

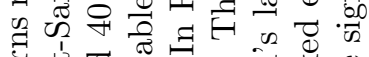

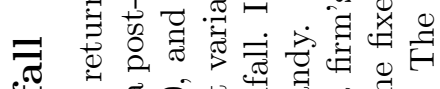

† ๘ี

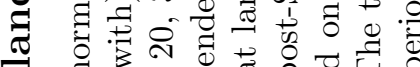

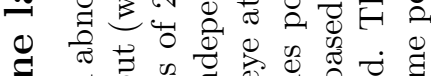

สี ठี

.

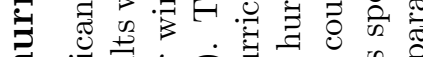

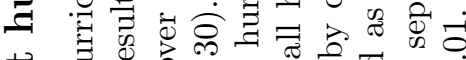

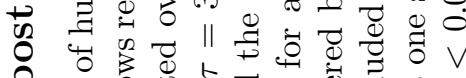

2 .

प

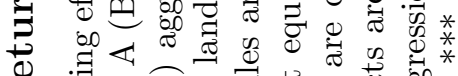

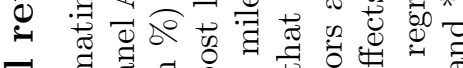

శี

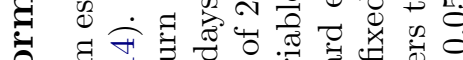

월

పี

《.

o

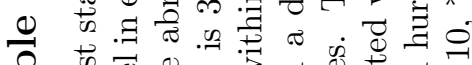

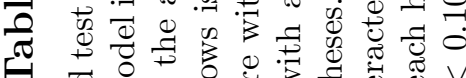

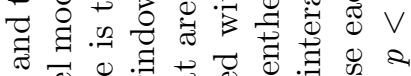

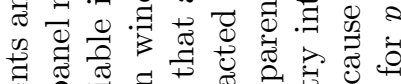

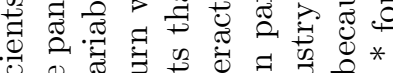

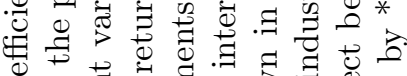

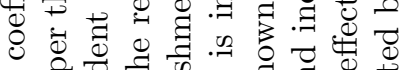

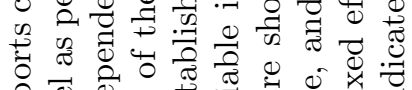

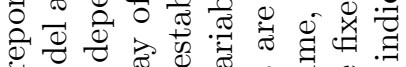

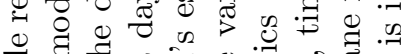

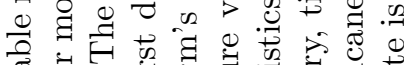

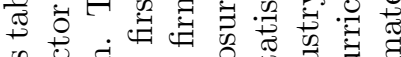

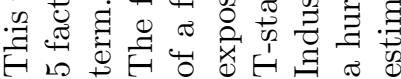

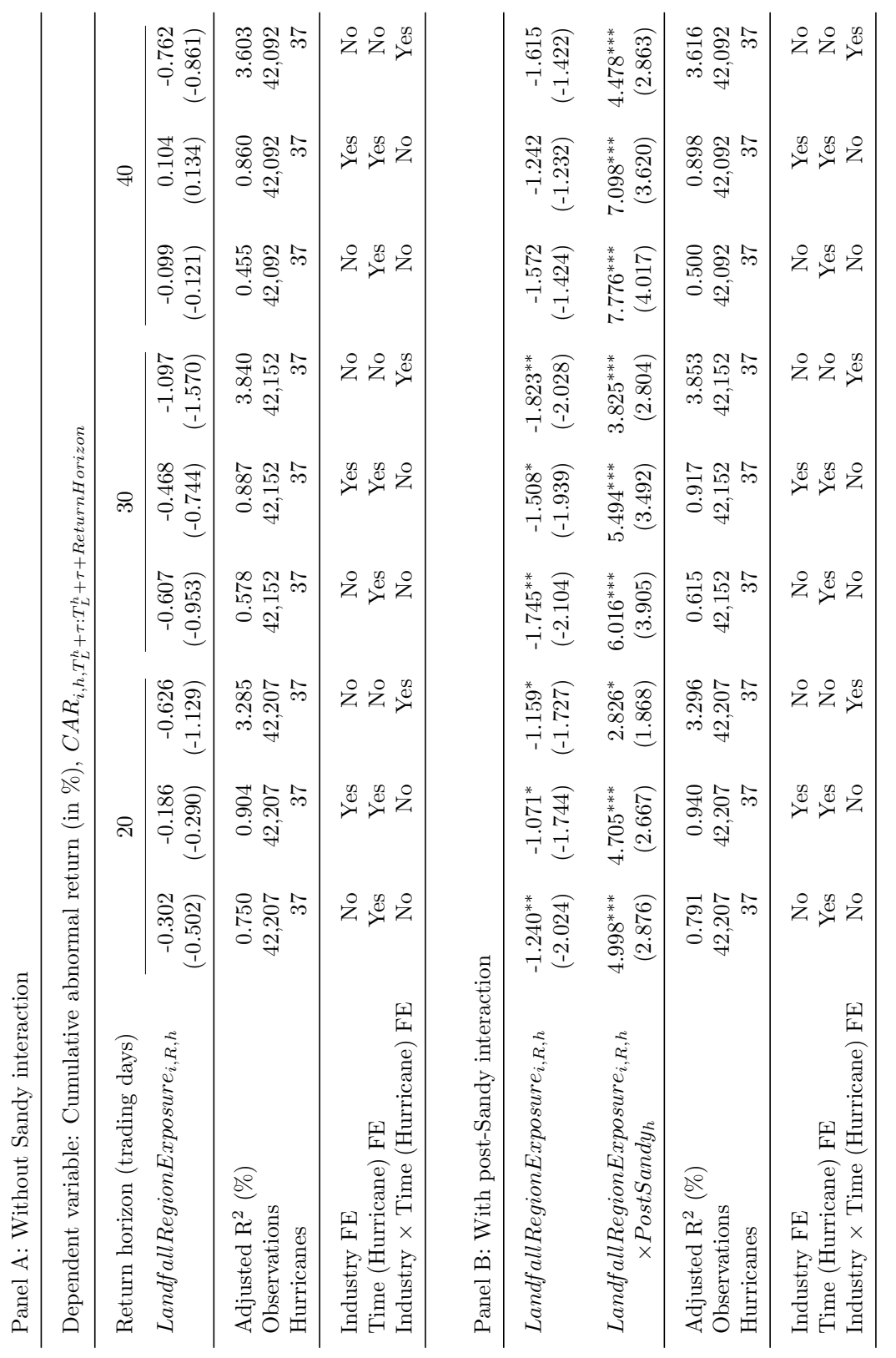




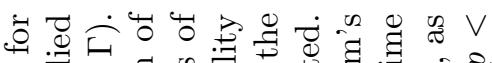

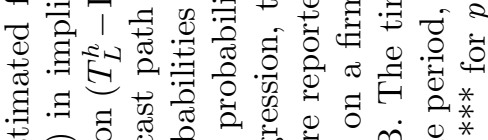

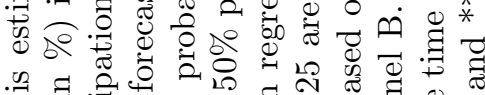

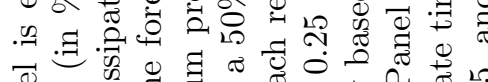

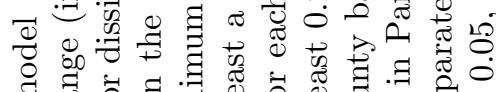

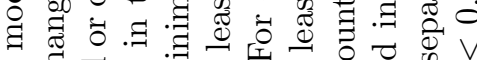

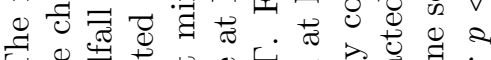

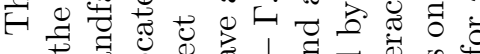

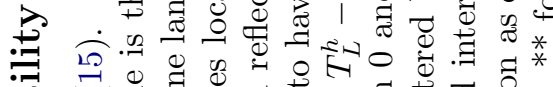

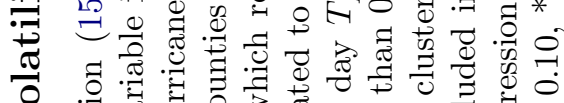

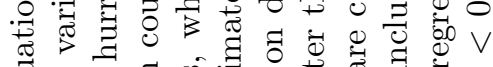
ర :

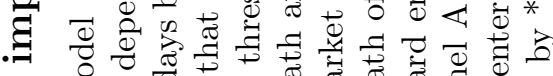

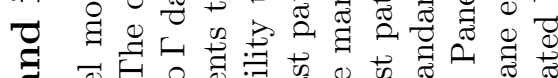
ส

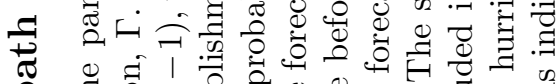
$2 \pm$.

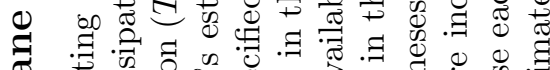

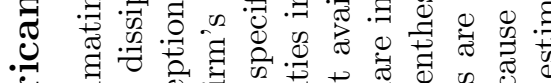

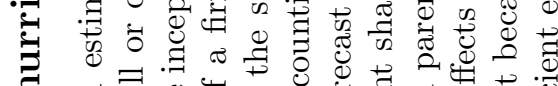

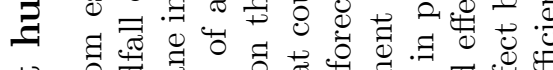
药 ن D. 穴 $\ddot{0}$ क

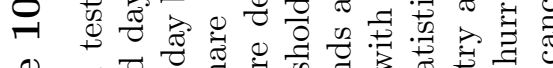

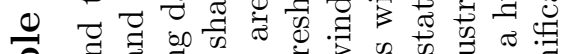

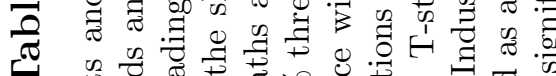

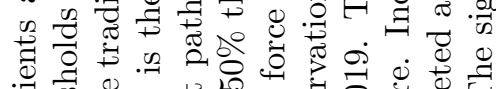

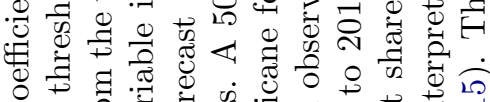

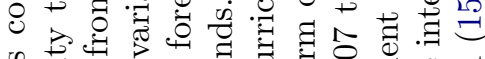
艁: :

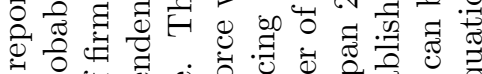
o

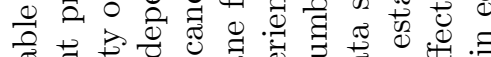

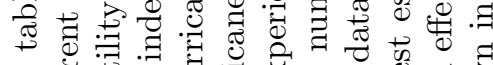

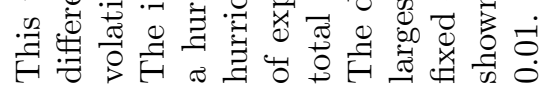

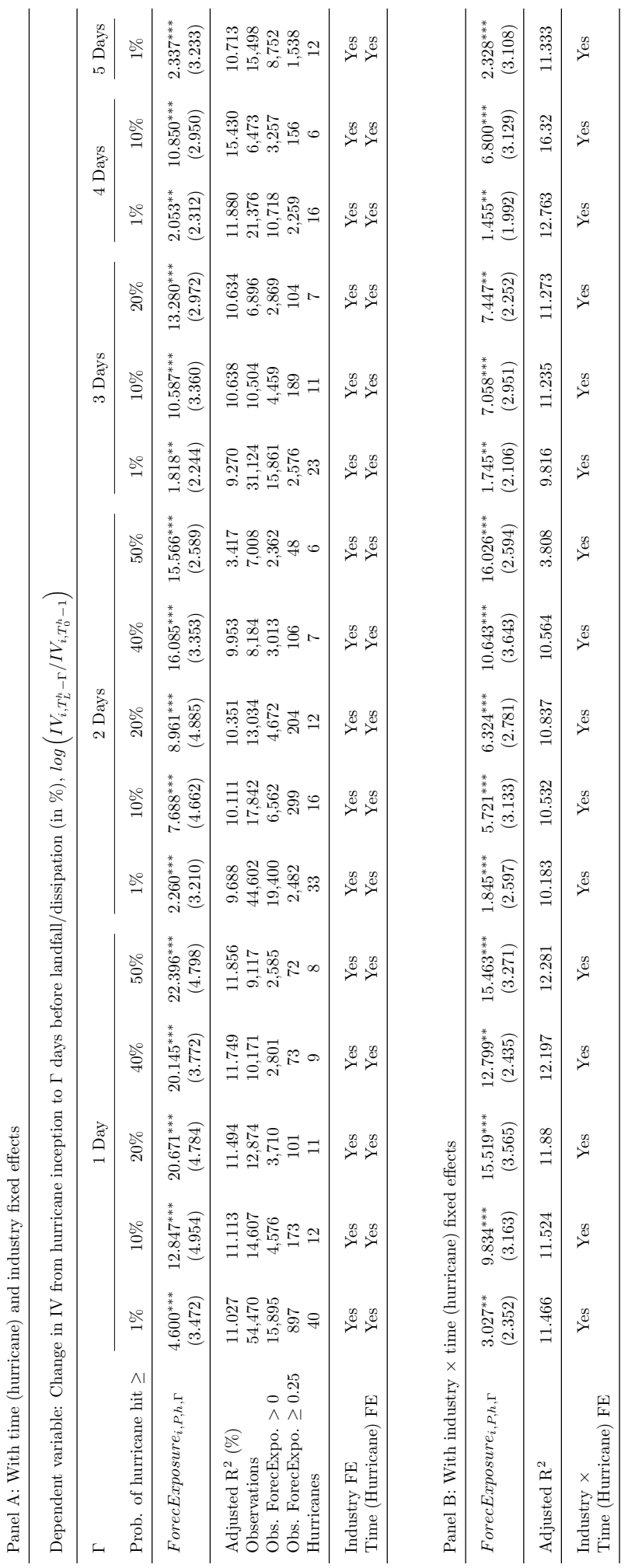




\section{Table 11: Hurricane season outlook effects on implied volatility}

This table reports the coefficients and test statistics when estimating the panel model in equation (16). The dependent variable is the change (in \%) in implied volatility of firm $i$ from the last trading day before NOAA's outlook for the hurricane season is released $\left(T_{0}^{s}-1\right)$ to 5 trading days thereafter $\left(T_{0}^{s}+5\right)$. Longer-dated options that cover the majority of the hurricane season (120 to 210 days to expiry) are used. The independent variable AboveNormalSeasonProbabilitys is the probability NOAA assigns to an "above average" hurricane season in terms of number of storms. In Panel A, the independent variable CoastalExposure ${ }_{i, s}$ is the share of a firm's establishments located in Atlantic and Gulf coastal counties. For columns (4) and (5), the counties on the Atlantic coast north of Florida are excluded from this measure. In Panel B, the independent variable HistoricalHurricaneExposure ${ }_{i, s}$ is the share of a firm's establishments (0 to 1$)$ located in counties that had a historical probability of being hit by a hurricane in a given season of at least 0.10 and 0.25 . The data span 2001 to 2019. T-statistics are shown in parentheses. Standard errors are clustered by county based on a firm's largest establishment share. Industry, time, and industry interacted with time fixed effects are included as specified. The significance of each coefficient estimate is indicated by ${ }^{*}$ for $p<0.10,{ }^{* *}$ for $p<$ 0.05 , and $* * *$ for $p<0.01$.

Panel A: Atlantic and Gulf coast counties

\begin{tabular}{|c|c|c|c|c|}
\hline \multicolumn{5}{|c|}{ Dependent variable: Change in IV (in \%), $\log \left(\frac{I V_{i, T_{0}^{s}+5}}{I V_{i, T_{0}^{s}-1}^{s}}\right)$} \\
\hline \multirow[b]{2}{*}{ CoastalExposure $_{i, s}$} & \multicolumn{2}{|c|}{ All coastal counties } & \multicolumn{2}{|c|}{ Excl. counties north of FL } \\
\hline & $\begin{array}{r}0.356 \\
(0.740)\end{array}$ & $\begin{array}{r}0.356 \\
(0.755)\end{array}$ & $\begin{array}{r}1.229^{*} \\
(1.940)\end{array}$ & $\begin{array}{r}1.092 \\
(1.624)\end{array}$ \\
\hline $\begin{array}{l}\text { CoastalExposure }_{i, s} \\
\quad \times \text { AboveNormalSeasonProb }_{s}\end{array}$ & $\begin{array}{r}0.187 \\
(0.179)\end{array}$ & $\begin{array}{r}0.193 \\
(0.974)\end{array}$ & $\begin{array}{r}-1.122 \\
(-0.718)\end{array}$ & $\begin{array}{r}-0.732 \\
(-0.590)\end{array}$ \\
\hline Adjusted $\mathrm{R}^{2}(\%)$ & 5.157 & 5.696 & 5.161 & 5.700 \\
\hline Observations & 21,117 & 21,117 & 21,117 & 21,117 \\
\hline Total firm obs. with exposure $>0 \%$ & 17,738 & 17,738 & 13,439 & 13,439 \\
\hline Total firm obs. with exposure $\geq 25 \%$ & 11,404 & 11,404 & 2,291 & 2,291 \\
\hline Industry FE & Yes & No & Yes & No \\
\hline Time FE & Yes & No & Yes & No \\
\hline Industry $\times$ Time FE & No & Yes & No & Yes \\
\hline
\end{tabular}

Panel B: Counties selected based on historical probability of being hit

\begin{tabular}{|c|c|c|c|c|}
\hline \multirow[b]{2}{*}{ HistoricalHurricaneExposure $_{i, s}$} & \multicolumn{2}{|c|}{ Counties with prob. $\geq 0.10$} & \multicolumn{2}{|c|}{ Counties with prob. $\geq 0.25$} \\
\hline & $\begin{array}{r}0.565 \\
(1.095)\end{array}$ & $\begin{array}{r}0.514 \\
(1.020)\end{array}$ & $\begin{array}{r}0.463 \\
(0.574)\end{array}$ & $\begin{array}{r}0.661 \\
(0.800)\end{array}$ \\
\hline $\begin{array}{l}\text { HistoricalHurricaneExposure }_{i, s} \\
\quad \times \text { AboveNormalSeasonProb }_{s}\end{array}$ & $\begin{array}{r}-0.225 \\
(-0.192)\end{array}$ & $\begin{array}{r}-0.188 \\
(-0.165)\end{array}$ & $\begin{array}{r}0.184 \\
(0.098)\end{array}$ & $\begin{array}{r}-0.333 \\
(-0.179)\end{array}$ \\
\hline Adjusted $\mathrm{R}^{2}(\%)$ & 5.162 & 5.697 & 5.149 & 5.687 \\
\hline Observations & 21,117 & 21,117 & 21,117 & 21,117 \\
\hline Total firm obs. with exposure $>0 \%$ & 18,615 & 18,615 & 13,835 & 13,835 \\
\hline Total firm obs. with exposure $\geq 25 \%$ & 16,535 & 16,535 & 2,455 & 2,455 \\
\hline Industry FE & Yes & No & Yes & No \\
\hline Time FE & Yes & No & Yes & No \\
\hline Industry $\times$ Time FE & No & Yes & No & Yes \\
\hline
\end{tabular}




\section{Table 12: Implied volatility post landfall with industry interactions}

This table reports coefficients and test statistics from estimating the panel model in equation (6) with industry dummy interaction terms added. The dependent variable is the change (in \%) in implied volatility of firm $i$ from the day before hurricane inception $\left(T_{0}^{h}-1\right)$, until 1 week (5 trading days) after landfall $\left(T_{L}^{h}+5\right)$. The independent variable is the share (from 0 to 1 ) of a firm's establishments that are within a 200-mile radius around the hurricane eye at landfall. The data span 1996 to 2019. T-statistics are shown in parentheses. The standard errors are clustered by county based on a firm's largest establishment share. Industry, time, and industry interacted with time fixed effects are included as specified. The time fixed effect can be interpreted as a hurricane fixed effect, as we include a separate time period in the panel for each hurricane as shown in equation (6). The significance of each coefficient estimate is indicated by $*$ for $p<$ $0.10,{ }^{* *}$ for $p<0.05$, and ${ }^{* * *}$ for $p<0.01$.

Dependent variable: Change in IV (in \%), $\log \left(I V_{i, T_{L}^{h}+5} / I V_{i, T_{0}^{h}-1}\right)$

\begin{tabular}{|c|c|c|c|c|c|c|c|}
\hline & \multicolumn{7}{|c|}{ Industry interacted with LandfallRegionExposure ${ }_{i, R, h}$} \\
\hline & Manufacturing & Wholesale & Services & Transport & Retail & Mining & Construction \\
\hline LandfallRegionExposure ${ }_{i, R, h}$ & $\begin{array}{r}5.626^{* * *} \\
(3.270)\end{array}$ & $\begin{array}{l}3.284^{* *} \\
(2.396)\end{array}$ & $\begin{array}{r}3.984^{* * *} \\
(2.588)\end{array}$ & $\begin{array}{l}3.235^{* *} \\
(2.584)\end{array}$ & $\begin{array}{r}3.801^{* * *} \\
(2.777)\end{array}$ & $\begin{array}{l}2.918^{* *} \\
(2.223)\end{array}$ & $\begin{array}{r}3.858^{* * *} \\
(2.821)\end{array}$ \\
\hline $\begin{array}{l}\text { LandfallRegionExposure } e_{i, R, h} \\
\quad \times \text { Industry }_{i}^{g}\end{array}$ & $\begin{array}{l}-4.280^{*} \\
(-1.926)\end{array}$ & $\begin{array}{r}10.586^{* *} \\
(2.272)\end{array}$ & $\begin{array}{r}-1.537 \\
(-0.618)\end{array}$ & $\begin{array}{r}3.501 \\
(0.953)\end{array}$ & $\begin{array}{r}-1.661 \\
(-0.406)\end{array}$ & $\begin{array}{l}5.444^{* *} \\
(2.223)\end{array}$ & $\begin{array}{r}-9.178^{* * *} \\
(2.821)\end{array}$ \\
\hline Adjusted $\mathrm{R}^{2}(\%)$ & 12.414 & 12.414 & 12.402 & 12.405 & 12.401 & 12.411 & 12.404 \\
\hline Observations & 38,881 & 38,881 & 38,881 & 38,881 & 38,881 & 38,881 & 38,881 \\
\hline Observations in interacted industry & 19,256 & 1,487 & 7,696 & 4,163 & 3,303 & 2,148 & 614 \\
\hline Hurricanes & 37 & 37 & 37 & 37 & 37 & 37 & 37 \\
\hline Industry FE & Yes & Yes & Yes & Yes & Yes & Yes & Yes \\
\hline Time (Hurricane) FE & Yes & Yes & Yes & Yes & Yes & Yes & Yes \\
\hline
\end{tabular}

